\title{
LAS FORMAS DE LA COOPERACIÓN Introducción a una metodología de análisis de los procesos cooperativos en la construcción del paisaje
}

\author{
Javier Rocamonde Lourido \\ Escuela Técnica Superior de Arquitectura de Barcelona (Universidad Politécnica de Catalunya) \\ Director de la tesis en curso: Joaquín Sabaté \\ Co-Directora de la tesis en curso: Melisa Pesoa \\ rocamondelourido@gmail.com
}

\section{RESUMEN}

Existen tantos paisajes como miradas sensibles al territorio. Esta investigación se aproxima al paisaje desde la perspectiva de la gobernanza y de los agentes que lo construyen. En este artículo se introduce una metodología de análisis que pretende establecer vínculos entre los procesos cooperativos, con los que algunas comunidades se adaptan al medio físico y social que habitan, y las formas del paisaje que resultan de ellos. En él confluyen dos líneas de trabajo: una deductiva, que plantea una serie de hipótesis teóricas generales; y otra inductiva, que pretende verificarlas desde lo particular. Para testar y afinar la metodología de trabajo, en esta ocasión se aplica a dos arquitecturas con un papel muy relevante en el relato de la industria textil vinculada al río Llobregat: la casa solariega Teixidor-Bassacs y la Torre del Amo de la colonia Viladomiu Nou.

Palabras Clave: morfología, tipología, cooperación, gobernanza, paisajes culturales

\begin{abstract}
There are as many landscapes as sensitive approaches to the territory. This research looks to the landscape from the perspective of governance and stakeholders. This article is an introduction to an analysis methodology that seeks to stablish links between cooperative processes and landscape forms. Two work lines converge in the article: one deductive, which raises a series of general theoretical hypotheses; and another inductive, which tries to verify them looking to the specific. To nuance this method it is tested with two architectures with a relevant role in the story of the textile industry in the Llobregat River: the Teixidor-Bassacs house and the Viladomiu Nou owner's house.
\end{abstract}

Key words: morphology, typology, cooperation, governance, cultural landscapes 


\section{INTRODUCCIÓN}

Este artículo se enmarca en una investigación en curso $^{1}$ que indaga en la relación entre la gobernanza y la morfología de algunos paisajes productivos vinculados a los bienes comunes ${ }^{2}$. Más concretamente, se aborda aquí una introducción a la metodología de análisis tipológico que se pretende aplicar a diferentes casos de estudio, con la intención de establecer una taxonomía de las formas que resultan de los procesos cooperativos en la construcción del paisaje. Para poner a prueba y afinar el método de análisis, en esta ocasión se pone el foco en dos arquitecturas vinculadas a la producción textil en el área de influencia del río Llobregat en el Baix Berguedà.

La primera parte del artículo presenta un breve recorrido por el estado del arte de los principales campos de conocimiento que conforman el marco teórico de la investigación. A continuación, se sintetiza la metodología de análisis y se introduce el material analizado: la casa Teixidor-Bassacs y la Torre del Amo de la colonia Viladomiu Nou. Tras un recorrido por el relato de las dos arquitecturas, éstas se comparan gráficamente. Finalmente, se extraen algunas conclusiones relacionadas con la principal pregunta de investigación que motiva el trabajo: ¿En qué medida estas dos arquitecturas son el reflejo, o la materialización física de los procesos cooperativos, que caracterizan la producción en las distintas fases de su construcción?

\section{LA COOPERACIÓN EN LOS PAISAJES PRODUCTIVOS}

Cooperar significa "obrar juntamente con otro u otros para la consecución de un fin común"3. El paisaje es una construcción social resultado de la cooperación de agentes, unidos con la finalidad de sobrevivir de la mejor forma posible, ante los retos que les plantea el medio físico y social que habitan. Sin embargo, esta cooperación no siempre está exenta de complicaciones. Muchas veces los agentes involucrados en la génesis de un paisaje están enfrentados por intereses contrapuestos. En ocasiones sus diferencias afectan su capacidad para cooperar, o provocan dinámicas competitivas. En otros casos, la cooperación es impuesta severamente por una minoría, que obliga a colaborar a los demás en beneficio propio. Solo en determinadas circunstancias esta cooperación adquiere configuraciones que posibilitan un intercambio justo entre individuos diferentes.

Esta investigación se aproxima a algunos paisajes productivos con el objetivo de identificar vínculos entre la cooperación y la morfología resultante. La mirada propuesta se sitúa en la confluencia de dos conceptos emergentes y sobre los que la discusión aún permanece abierta: los paisajes culturales y la gobernanza. A continuación, se destacan algunas aportaciones relevantes sobre de estas temáticas.

\section{Paisaje y Patrimonio}

La preocupación por la preservación del patrimonio es un fenómeno que no empieza a tener importancia hasta el siglo XIX. Si bien es cierto que cada vez más personas muestran interés por el mismo, su conservación representa a veces una traba en la modernización de algunos aspectos de la sociedad.

Desde una perspectiva histórica, se consideran pioneros en la preservación del patrimonio a Ruskin (Inglaterra 1819-1900), con una aproximación que bebe del romanticismo de la época del caminante de Friedrich; y a Eugène Viollet-le-Duc (Francia 1814-1879), con una visión más próxima al racionalismo y a las ideas de la ilustración heredadas de Goethe -fascinado por la antigüedad- o a Heinrich Schliemann -con su obsesión por Troya-. En 1834 el escritor, historiador y arqueólogo Prosper Merimée (1803-1870) sucede a Ludovic Vitet como Inspector General de Monumentos Históricos en París. Es él quien encarga a Viollet-le-Duc la reforma de la abadía de Vézelay; que le lleva a una profunda reflexión sobre la restauración de monumentos, plasmada en su Diccionario razonado de la arquitectura francesa desde el siglo XI hasta el XVI (Viollet-le-Duc, 1858). En el contexto del Segundo Imperio Francés se enfrentan la modernización de París -promovida por Napoleón

\footnotetext{
${ }^{1}$ Las ideas planteadas en este artículo son una síntesis de la metodología que se está desarrollando en la tesis doctoral: La Khôra de los Comunes, que continúa la investigación iniciada en (Rocamonde, Sabaté y Orduña 2017).

${ }^{2}$ La idea histórica de bien común hace alusión a un recurso de uso y gestión colectivo, generalmente de carácter natural (acequias, bosques comunales, caladeros pesqueros,...) y propio de comunidades rurales relativamente acotadas. Cabe destacar el trabajo de la doctora en ciencias políticas y premio Nobel en 2009 Elionor Ostrom (1990) sobre este tipo de bienes comunes.

Actualmente cuando hablamos del común o pro-común nos referimos a recursos más complejos que los bienes comunes históricos. El concepto actual va más allá de la titularidad legal o la naturaleza del recurso, poniendo el acento en la acción de reivindicarlo y gestionarlo como colectivo. Abundan las monografías sobre el tema entre las que se podrían destacar (Castro-Coma y Martí-Costa 2016; Hess 2008; Subirats y Rendueles 2016; Hardt y Negri 2009).

${ }^{3}$ Definición de la RAE http://dle.rae.es/?id=Aid2o2x
} 
III y el Barón Haussmann- con la preservación del patrimonio heredado -defendida por Merimée, Victor Hugo o Gustavo Doré. (Sabaté Bel 2005, 2007)

Hasta finales del siglo XIX las consideraciones sobre la preservación del patrimonio se refieren a monumentos aislados y no se considera relevante el vínculo entre lo construido y su entorno. Prueba de ello es el constante expolio de piezas o monumentos completos, desvinculándolos de su contexto y encerrándolos en museos. Esta perspectiva cambia con la extensión del concepto de patrimonio y la aparición del concepto de paisaje cultural. Como precursores cabe citar a los geógrafos Friedrich Ratzel (Alemania 1844-1904), que reflexiona sobre el determinismo del medio geográfico; Otto Schlütter (Alemania 1872-1959), y su idea de Landschaft; y Vidal de la Blache (Francia 1845-1918), que teoriza sobre la influencia mutua entre sociedad y naturaleza; o los sociólogos Emile Durkheim y Federic Le Play, que defienden la relación entre paisaje y paisanaje (Sabaté Bel 2005).

A principios del siglo XX, en un breve texto, La morfología del paisaje (1925), el geógrafo Carl O. Sauer plantea una perspectiva morfológica y antropocéntrica, en la que define paisaje cultural como el resultado de la acción de un grupo cultural sobre el paisaje natural. Esta aproximación dota de protagonismo a la comunidad -como agente generador de paisaje- y al tiempo -al revelar el proceso de modificación del medio natural-. Desde aquel entonces proliferan las investigaciones sobre los paisajes culturales, consolidando la continuidad entre dos conceptos que anteriormente parecían alejados: paisaje y patrimonio. Prueba de la relevancia que cobra el concepto de Paisaje Cultural, es el esfuerzo de la UNESCO, desde la Convención del Patrimonio Mundial de 1972, por definirlo y distinguir diversas categorías (UNESCO 2006).

\section{Gobernanza y Cooperación}

La gobernanza es un concepto que viene de antiguo y que se recupera a finales del siglo XX. Alude a los procesos de gobierno de cualquier organización social, sean éstos formales o informales. Se diferencia del gobierno tradicional en que se centra menos en las estructuras jerárquicas de estado y más en las dinámicas sociales, poniendo el foco en el rol de agentes -tanto públicos como privados- que establecen acuerdos para solventar problemas o crear oportunidades. Tradicionalmente se considera el gobierno como una acción unidireccional de los gobernantes hacia los gobernados. La gobernanza pone de manifiesto un modelo bidireccional en el que se entremezclan las relaciones entre agentes (Bevir 2012; Kooiman 2005). La reciente popularidad del concepto de gobernanza está íntimamente ligada con los cambios en la concepción del territorio que implica el desplazamiento de la dimensión territorial del Estado-nación -"entendido como un espacio continuo que ocupa una parte de la superficie de la tierra"-, a la red -"un espacio formado por puntos discretos vinculados por líneas de relación, no por continuidades físicas"- (Brugué, Gomà y Subirats 2005). Autores como Dematteis defienden que el gobierno de esta nueva realidad territorial debe apoyarse en la gobernanza de las redes, entendida como interacción estratégica con los sujetos que "debaten, compiten, negocian, cooperan, es decir conforman redes relacionales" (Dematteis 2006).

Se parte aquí de las teorías sobre la gobernanza como modelo epistemológico, para analizar las relaciones entre los agentes que modifican el territorio y coproducen el paisaje. Para ello se observan los distintos matices que cobra la gobernanza en relación a los modelos productivos a lo largo de la historia; desde las formas más jerárquicas -propias de los modelos industriales-, a los tipos más horizontales que emergen en la actualidad y que autores como Kooiman (2005) definen como co-gobernanza -caracterizada por la colaboración o cooperación de agentes-. En esta línea, el sociólogo estadounidense Richard Sennett dedica su obra Juntos (2012) a analizar la evolución de la cooperación a lo largo de la historia, tratando de responder a la pregunta de cómo podemos vivir juntos, aun siendo tan diferentes. Para ello utiliza una serie de conceptos y casos de estudio concretos y de naturaleza diversa, que demuestran cómo a lo largo de la historia, la necesidad de entenderse y cooperar con los otros, es una cuestión de habilidad, más que de posicionamiento moral (Sennett 2012, p. 10). Este autor define la cooperación como "un intercambio en el cual los participantes obtienen beneficios del encuentro" (Sennett 2012, p. 18). A diferencia del tribalismo, que "asocia solidaridad con los semejantes y agresión contra los diferentes" (Sennett 2012, p. 16), Sennett se centra en "el difícil tipo de cooperación que trata de reunir a personas con intereses distintos, o incluso en conflicto, que no se caen bien, que son desiguales o que sencillamente no se entienden" (Sennett 2012, p. 19).

Aunque abundan estudios sobre los paisajes culturales, y también aquellos que tratan la gobernanza, son menos habituales aproximaciones que parten de la confluencia de ambas temáticas. Esa es la perspectiva de esta investigación, planteando la lectura de algunos ámbitos productivos con valor patrimonial, con la intención de desvelar los modelos de gobernanza que se esconden tras las formas del paisaje. 


\section{UNA METODOLOGÍA DE ANÁLISIS DE LOS PROCESOS COOPERATIVOS EN LA CONSTRUCCIÓN DEL PAISAJE}

Con el objetivo de desvelar vínculos entre los procesos cooperativos en la construcción del paisaje y las formas que resultan de ellos, se recurre a un análisis gráfico comparativo. Se trata de una aproximación a una metodología de análisis que permite comparar la evolución morfológica de diversos casos de estudio y la relación de los agentes que los producen a lo largo del tiempo. Principalmente la comparación se lleva a cabo a través de los siguientes análisis:

\section{- Cronología del relato}

A través de la recopilación y síntesis de estudios y documentos históricos, previamente elaborados por otros autores, se construye una narrativa de los paisajes del textil en el Baix Berguedà. Este relato se presenta dividido en tres períodos definidos por el modelo productivo que los caracteriza: producción preindustrial, industrial, y biopolítica ${ }^{4}$ que emerge en la actualidad.

\section{- Diagramas de cooperación}

Se identifican los agentes más relevantes del relato en cada una de las fases y se sintetizan en diagramas de gobernanza las relaciones entre ellos. Este artículo no entra en profundidad en esta dimensión del análisis. Sin embargo, se toman como premisas algunas conclusiones obtenidas en un trabajo previo (Rocamonde, Sabaté y Orduña 2017) donde se presenta una serie de diagramas de gobernanza que sintetizan las relaciones entre agentes en algunos paisajes productivos vinculados al Llobregat.

\section{- Taxonomía de las formas de los paisajes del trabajo}

Mediante el dibujo en las distintas escalas de cada uno de los casos, se elabora una taxonomía de formas resultado de procesos cooperativos. Este material es la base para la comparación final. Este artículo representa una primera aproximación a la dimensión morfológica del análisis, con la intención de empezar a acumular el material que en fases más avanzadas de la investigación dará lugar a un atlas de formas resultado de la cooperación en paisajes productivos.

A continuación, se aplica esta metodología a dos construcciones que juegan un papel fundamental en la organización de la producción textil vinculada al río Llobregat en el Baix Berguedà: la casa solariega Teixidor-Bassacs y la Torre del Amo de la colonia Viladomiu Nou, ambas ubicadas en el municipio de Gironella. Dada su capacidad de adaptación programática a lo largo del tiempo, representan un ejemplo idóneo para analizar la evolución de la organización social y los modelos productivos en los últimos dos siglos. Cabe aclarar que este análisis gráfico se aproxima a la escala arquitectónica desde una perspectiva territorial. Aunque el conjunto de la investigación deberá, sin duda, analizar también las escalas intermedias, se opta ahora por un análisis tipológico para contrastar desde lo más específico e individual -con un método inductivo- aquellas premisas generales planteadas hasta la fecha -de manera deductiva-.

\footnotetext{
${ }^{4}$ Hardt y Negri (2009, p. 73) definen la producción biopolítica basándose en la reinterpretación de la idea de biopolítica de Michel Foucault : "Nuestra lectura no sólo identifica la biopolítica con las potencias productivas localizadas de la vida - es decir, la producción de afectos y lenguajes a través de la cooperación social y de la interacción de cuerpos y deseos, la invención de nuevas formas de relación con uno mismo y con los demás, etc.-, sino que afirma también la biopolítica como la creación de nuevas subjetividades que se presentan a vez como resistencia y como desubjetivación."
} 


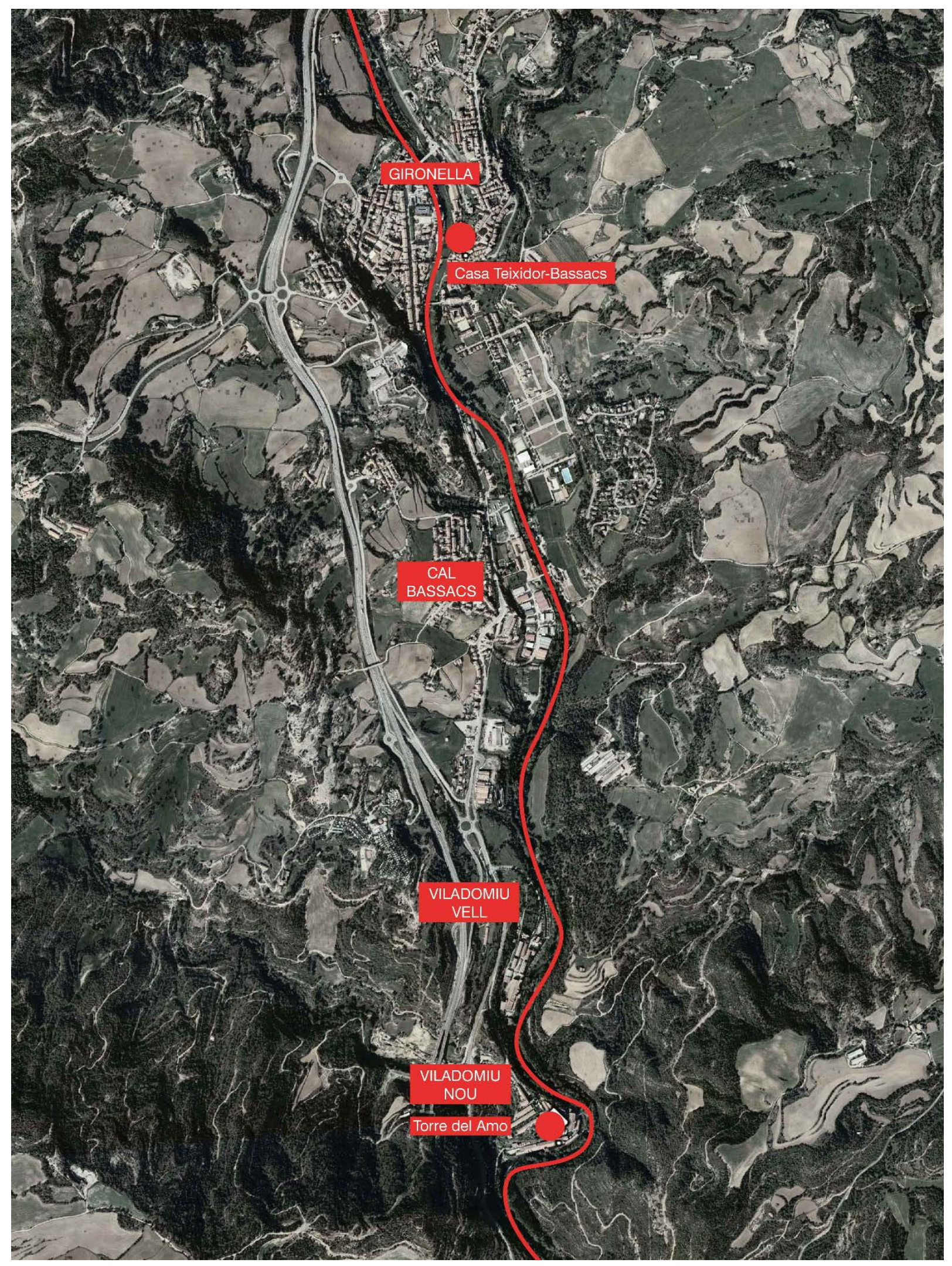

FIGURA 1. Situación de los casos de estudio. Elaboración propia sobre imagen aérea de Google Earth. 


\section{LA COOPERACIÓN DISPERSA EN LA PRODUCCIÓN PREINDUSTRIAL}

Como demuestra Pere Vall (1997), en el ámbito del Baix Berguedà, son los propios emprendedores locales, los que llevan a cabo la industrialización. Procedentes de familias vinculadas a la artesanía textil, devienen empresarios y colonizan el cauce del río con fábricas, que con el tiempo se transforman en colonias. Para ello acumulan previamente los conocimientos del oficio y los recursos económicos necesarios. Según Vall, existe una continuidad entre las villas, donde radican los artesanos textiles, con la industria surgida en el cauce del río Llobregat.

Antes del siglo XIX, la producción textil tiene un carácter artesanal. Los paraires ${ }^{5}$ son menestrales que se encargan de comercializar los tejidos y coordinar un sistema de producción disperso: "El sistema funcionaba con el núcleo urbano como centro organizador y las masías de los alrededores que trabajaban para el: Unos cardaban la lana, otros hilaban y otros tejían" (Correa Lloreda 2003, p. 25). Gironella o Sallent son ejemplo de estas villas donde prolifera el textil desde el siglo XVIII y especialmente durante el siglo XIX. En este contexto, la familia payesa tradicional basa su subsistencia en la complementariedad entre la agricultura, principalmente vinícola en rabassa morta ${ }^{6}$, y la producción textil: "Els rendiments agraris son insuficients per assegurar la reproducció de la unitat familiar. La dona fila a casa per a un paraire i complementa l'ingrés agrícola assumit per I’home" (Vall i Casas 1999, p. 14).

Los Teixidor-Bassacs y los Viladomiu son dos de estas familias tradicionales de menestrales vinculados al textil durante varias generaciones (Serra Rotés 2013, p. 25). La casa solariega (pairal) de la familia TeixidorBassacs representa un ejemplo de la tipología arquitectónica donde reside la familia de menestrales, que coordina el sistema de cooperación disperso, pero también es el lugar donde se realiza una parte del proceso de producción textil: el tejido. Se trata, por tanto, de una vivienda productiva, que también alberga la función logística, de control y de representación. Hasta la casa llegan los hilos (primero de lana y después de algodón), previamente elaborados en las masías próximas. En la cuadra de telares, como se denomina al taller ubicado en la planta baja, se preparan los tejidos para posteriormente ser distribuidos.

A lo largo del siglo XVIII los Teixidor-Bassacs y los Viladomiu pasan de menestrales a industriales, concentrando sus negocios textiles - previamente dispersos-, en fábricas movidas por la fuerza del Llobregat. Para hacer frente a la inversión que supone la construcción de fábricas, se asocian con otras familias de tradición artesana. En este proceso incrementan su riqueza y su influencia política ${ }^{7}$. Paralelamente, la mano de obra que trabaja para los menestrales se incorpora a las nuevas industrias sin perder del todo su relación con la agricultura (Vall i Casas 1999).

Un antecedente capital a la hora de comprender la evolución del modelo de producción textil preindustrial y su evolución en las colonias, es la larga tradición del aprovechamiento energético de las corrientes fluviales. Ésta se remonta a las máquinas hidráulicas de los romanos, recuperadas en los siglos XV y XVI. Continuando esta tradición, en el siglo XVIII los molinos de agua proliferan por toda Catalunya (Tarragó et al. 1987). Las colonias textiles suponen una evolución de la colonización hidráulica de los siglos anteriores. Muchos de estos molinos tradicionales pertenecen a la comunidad local y son gestionados de forma cooperativa. Según el inventario de los bienes del común de Gironella del año 1855 (Serra Rotés 2013, p. 22), el molino harinero de la villa es un ejemplo de estas infraestructuras comunitarias.

A mediados del siglo XIX, en el contexto de decadencia tras la Primera Guerra Carlista y la desamortización de los bienes comunales, el modelo de producción rural apoyado en los gremios y los bienes comunes entra en crisis. Esto queda patente con la subasta en 1864 del molino de Gironella, que compra Ramón Alsina con la intención de transformarlo en una fábrica textil. Como afirma Vall: "Molts dels molins del segle XVIII, establerts amb l'expansió comercial de l'agricultura dels cereals, aprofiten la ubicació i sovint les construccions de molins medievals. La ruïna econòmica dels pagesos d'aquest molins en èpoques de males collites permet a l'industrial comprar el seu capital agrari a baix preu" (Vall Casas y Sabaté Bel 1997).

\footnotetext{
${ }^{5}$ Paraire (Catalán) o Pelaire (Castellano):"Persona encargada de preparar la lana que ha de tejerse" http://dle.rae.es/?id=SMkqtVN.

${ }^{6}$ Rabassa Morta: "El contracte exigeix la plantació de vinya i el pagament d'una quarta part dels fruits, i té una durada que equival a la vida dels ceps. En definitiva, significa l'accés del petit pagès (rabassaire) a la quasipropietat de la terra fet que l'estimula a una elevada inversió de treball (Vall i Casas 1999, p. 14)

${ }^{7}$ Tomás Viladomiu Bertran, nacido en Sallent en 1809, llega a ser alcalde de la villa durante los años 1848 y 1849.
} 


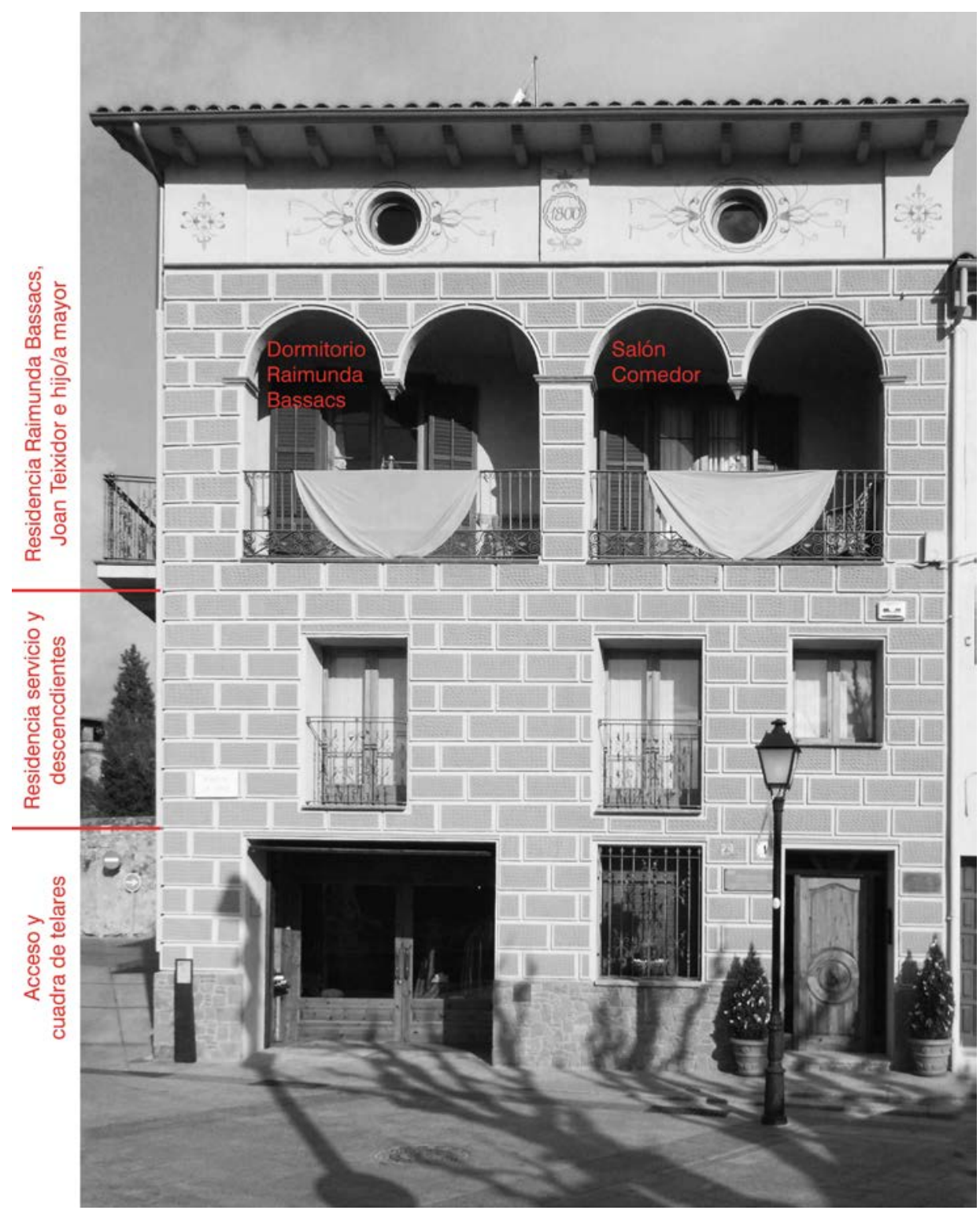

FIGURA 2. Casa Teixidor-Bassacs. Elaboración propia.

\section{LA COOPERACIÓN JERÁRQUICA EN LA PRODUCCIÓN INDUSTRIAL}

El origen de las colonias textiles es también la historia de una lucha por el control del agua. Ésta se salda con el cercamiento ${ }^{8}$ del Llobregat y con al menos una generación de trabajadores dentro de los muros de los recintos industriales.

Como defiende Llorenç Ferrer (2005), gran parte de las colonias industriales del Llobregat se financian con el excedente económico extraído de la propia industria textil a lo largo del siglo XIX. En general la fundación de las colonias textiles representa un cambio en la lógica empresarial de los fabricantes. Las industrias del siglo XIX, pertenecen generalmente a sociedades que aglutinan distintas familias. Sin embargo, y salvo alguna excepción, las colonias se conciben como empresas familiares que concentran los recursos de distintos proyectos previamente independientes.

La familia Teixidor-Bassacs se adapta a las nuevas dinámicas y concentra la producción en una fábrica vinculada al río. En 1861 Joan y Raimunda empiezan a comprar tierras en las proximidades del Llobregat,

\footnotetext{
${ }^{8}$ Marx expone la noción de enclosure (cercamiento) en capítulo de El Capital titulado La acumulación originaria (Marx 1867). En él describe el proceso secular de cierre y privatización de los terrenos comunales ingleses en los siglos XVII al XIX en favor de los terratenientes (convertidos en capitalistas).
} 
para construir una fábrica en lo que más tarde se conocería como Cal Bassacs (Serra Rotés 2013, p. 23). La nueva colonia se ubica a poco más de un kilómetro de su casa solariega en Gironella. Tal es la proximidad de ambos emplazamientos que desde los balcones de la casa en Gironella se puede ver la colonia Bassacs. Aunque este artículo se centra en la casa solariega Teixidor-Bassacs y la Torre del Amo de la colonia Viladomiu $\mathrm{Nou}^{9}$, Cal Bassacs cuenta asimismo con una Torre del Amo que también podría ser objeto análisis.

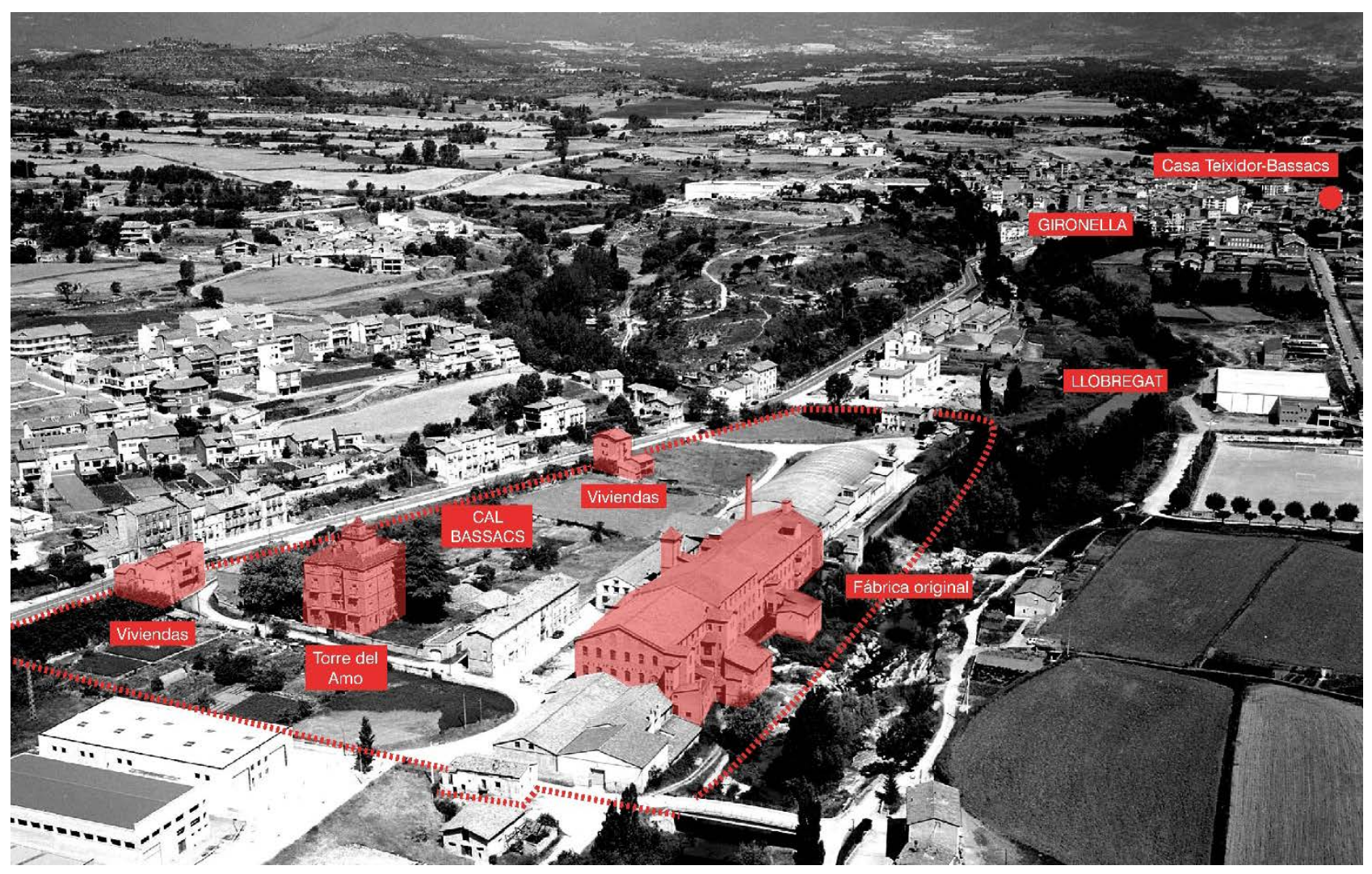

FIGURA 3. Cal Bassacs. Anotaciones sobre imagen aérea del PDU de las Colonias del Llobregat (Vall, Sabate et al. 2007)

El caso de las colonias Viladomiu Nou y Vell también surge de la reinversión de capitales dispersos en las diferentes sociedades de los Viladomiu. A principios de 1868, Tomàs Viladomiu entiende que su negocio textil en Sallent ya no puede crecer más y empieza a buscar un emplazamiento adecuado para una nueva fábrica. Poco tiempo después compra la primera parcela, en la masía de Cal Feliu, y empieza las obras de la fábrica. En paralelo, presenta la solicitud para acogerse a la ley de aguas, que le será concedida en 1871, eximiéndole de pagar la contribución industrial.

Es importante comprender la situación política del segundo tercio del siglo XIX, que genera la coyuntura favorable de la que se aprovechan las familias de industriales que establecen las colonias. En el segundo tercio del siglo XIX la colonización agraria del campo español continúa siendo una tarea pendiente. Por ello, uno de los principales objetivos del estado liberal entre los años 1833 y 1868 es su modernización. Para ello se aprueban una serie de normas, como las leyes de desamortización (Mendizabal, 1836 y Madoz, 1855), la ley de colonias de 1855 (relacionada con las desamortizaciones, la ley de ferrocarriles y la de sociedades anónimas de créditos), la ley de colonias de 1866 (dirigida al fomento del caserío rural y complementada con la ley de aguas) y la ley de colonias de 1868 (que pone las bases para el auténtico desarrollo de las colonias industriales) (Serra Rotés 2010, p. 242). Mediante estas leyes, el estado delega su responsabilidad de modernizar el territorio en la iniciativa privada, generando un marco jurídico fiscal que incentiva el establecimiento de industrias no agrícolas en zonas rurales. La condición de colonia ahorra al empresario el pago de impuestos por un periodo de quince a veinticinco años, además de posibles prórrogas, y el privilegio de ocupar cargos de representación pública, permiso de armas gratuito, para explotar canteras y construir hornos. También exime a los trabajadores de la colonia de realizar el servicio militar. A cambio, la ley obliga al industrial a sufragar los servicios básicos de educación (Serra Rotés 2010, p. 242). El trato de favor de la

\footnotetext{
${ }^{9}$ Se eligen estos dos ejemplos para el análisis gráfico debido a la amplia perspectiva que ilustran por su uso actual como museos o centros de interpretación de la producción textil que albergaron en el pasado.
} 
normativa hacia las colonias pronto genera enfrentamientos con los municipios, que no aceptan fácilmente los beneficios fiscales para estos núcleos al margen de su jurisdicción (Clua i Mercadal 1992; Vall i Casas 1999).

Con las colonias, los empresarios, además de aumentar su fortuna, sacian su sed de poder y popularidad. Los trabajadores, al ver reducidas cada vez más sus alternativas de subsistencia en el medio rural, obtienen estabilidad laboral y un lugar donde vivir. A cambio, aceptan unas durísimas condiciones de trabajo mal remunerado. Las colonias, en contraposición a la miseria que se extiende en el contexto, actúan como polos de atracción de población, generando movimientos que desplazan habitantes de Catalunya y del resto del estado hacia el cauce del Llobregat (Comas 2005).

Con el auge de las fábricas dependientes de la energía hidráulica también se genera un conflicto por el control del agua. A las desamortizaciones que habían privatizado los molinos tradicionales, se suman ahora las concesiones de aprovechamiento hidráulico que legalizan el uso privado de aguas comunes para actividades industriales. La ley de aguas de 1866, revisada en 1879, además de permitir utilizar el agua como fuente de energía gratuita, exime a los empresarios de pagar impuestos de contribución industrial durante diez años. El espíritu de esta norma considera que los aprovechamientos hidráulicos ahorran importaciones de carbón inglés. La ley beneficia a todos los empresarios, sea cual sea su actividad (Serra Rotés 2010, p. 243). En consecuencia empieza un intenso proceso especulativo con los saltos de agua del Llobregat (Vall i Casas 1999, p. 73-86).

En 1871 se pone en funcionamiento la fábrica de Viladomiu Vell, a nombre de la empresa familiar Viladomiu e Hijos. En su origen, consta de una potente turbina suiza, 18 cardos, 4.000 husos y 79 telares mecánicos, algunos de ellos traídos de otros negocios de la familia. La industria posee también un edificio para secar las piezas, una cerrajería, cuatro casas para los obreros y las caballerías; además de la casa donde pronto se traslada a vivir la familia Viladomiu. En esta primera fase, la falta de consistencia urbana, no permite aún hablar de un pueblo autónomo (Vall Casas y Sabaté Bel 1997).

Los primeros trabajadores de Viladomiu Vell, tras su apertura en 1871, viven en las habitaciones del segundo piso de la fábrica. El hecho de que el propio Tomás Viladomiu tenga en ese mismo espacio su residencia (hasta 1878), podría interpretarse como un gesto de proximidad con los trabajadores (Serra Rotés 2013, p. 26), quizás más propio de la época en la que era un menestral que de su nuevo rol de industrial. La solidaridad y la cercanía con la comunidad siempre fue una característica de la forma de ser (tarannà en catalán) de este industrial que los historiadores y cronistas de la época se han esforzado en resaltar. En su período de alcalde de Sallent, su biógrafo destaca la construcción del alcantarillado y nuevas calles, además del arreglo de caminos, la construcción de un nuevo cementerio, pero sobre todo, su papel durante la epidemia de cólera de 1854. Por ello el propio ayuntamiento le otorga un diploma con la Cruz de Beneficencia (Serra Rotés 2013, p. 25). Esta imagen es uno de los pilares fundamentales que caracteriza el modelo industrial paternalista, presente en mayor o menor medida en todas las colonias textiles.

El rápido éxito del proyecto de Viladomiu Vell se pone de manifiesto cuando en 1880, a pocos metros de la primera industria, empiezan las obras de construcción de otra fábrica, que posteriormente se conocerá como Viladomiu Nou. Tomàs Viladomiu es consciente de que para aprovechar la energía hidráulica al máximo es necesario establecer una nueva fábrica independiente de la anterior. Además del permiso de aprovechamiento del salto de agua, también consigue el estatuto de colonia para este nuevo proyecto. En 1882 se inaugura, con el nombre de "Clau de Sant Marc".

En 1883, se empieza a construir la iglesia de Viladomiu Vell, obra de Valentí Canudas de Casserres y se celebra la primera Fiesta Mayor. En 1885 se organizan las primeras Caramelles ${ }^{10}$ y se nombra al primer capellán de la colonia y un año después se organiza el primer coro. Este tipo de eventos tienen un papel capital en la articulación del modelo cooperativo. Como defiende Richard Sennett, estos rituales promueve la cooperación "salvando las apariencias" entre diferentes agentes y "disminuyendo la acidez corrosiva de las comparaciones odiosas" (Sennett 2012, p. 128).

\footnotetext{
${ }^{10}$ Canciones populares cantadas en pascua para celebrar la resurrección de Jesús.
} 
El párroco juega un papel fundamental en el modelo social paternalista, pues siempre fiel al amo, es el encargado de inculcar a la comunidad unos valores, enraizados en el Rerum Novarum ${ }^{11}$ de la iglesia católica, que favorecen el modelo cooperativo de la colonia y la docilidad de los trabajadores.

A pesar de la idiosincrasia condescendiente de los patrones y la función pedagógica de los párrocos, no siempre logran asegurar la paz social en las colonias. A partir de la reestructuración del sindicato textil "Las tres Clases de Vapor", en la década de 1880 , se inicia un período en el que la conflictividad laboral inunda los valles del Ter y del Llobregat. Estas protestas se saldan en el Llobregat con la fulminante derrota de los trabajadores y la consiguiente represión y despidos. En lo que se denomina "el pacte de la fam" se crean listas negras para negar trabajo en la comarca a unos seiscientos obreros (Enrech 2005; Serra Rotés 2010).

En la última década del siglo XIX desaparece la conflictividad del Alto Llobregat y se consolida el proyecto social paternalista. A los dos pilares mencionados con anterioridad (paternalismo y Rerum Novarum) se suma ahora el control social. En 1889 en la colonia Viladomiu, al igual que en muchas otras, se elevan las murallas que las separan literalmente del exterior, constituyéndose como auténticos "feudos industriales". Es aquí donde juegan un papel fundamental las torres del amo, que además de reafirmar la superioridad del patrón, actúan a modo de panópticos (Foucault 1979) desde los que poder controlar los movimientos de los obreros: "tota la vida social arribarà a estar controlada pel fabricant i el capellà, des de la festa major fins el grup de teatre, el casino o ateneu, passant per les anades i vingudes de la colònia al poble els diumenges" (Enrech 2005).
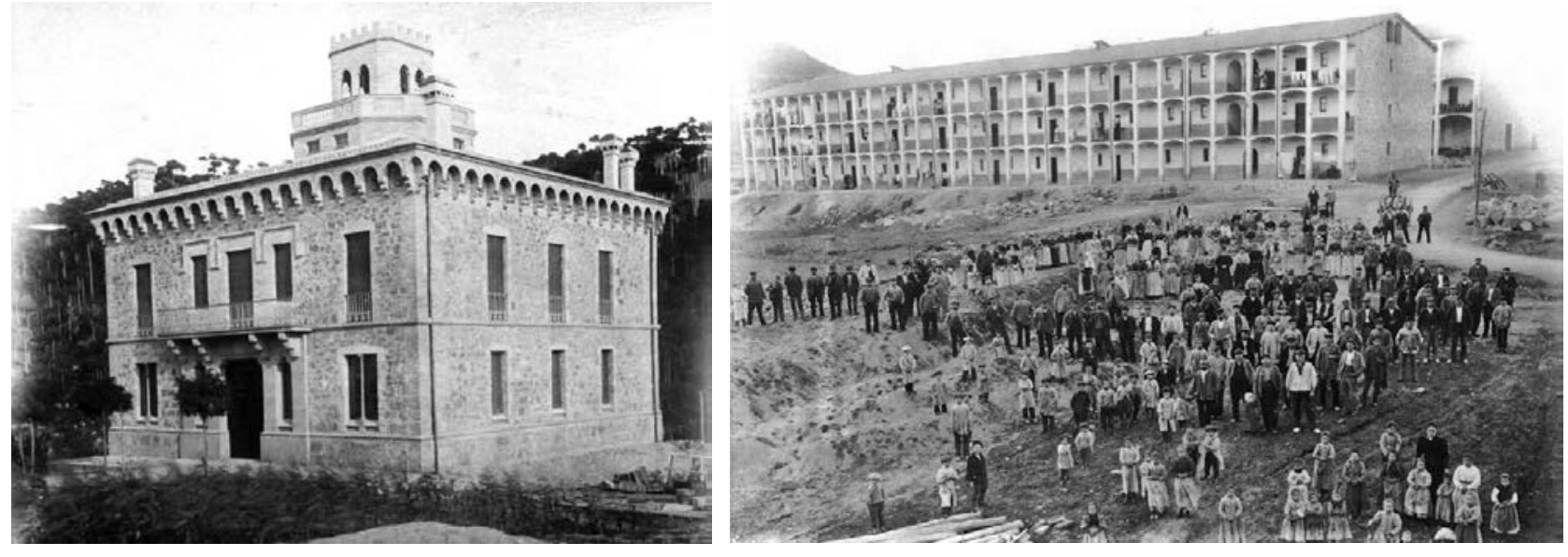

FIGURA 4. La torre del amo de Viladomiu Nou. Año 1905. Archivo Parque Fluvial del Llobregat. Reproducido en (Serra Rotés 2013 ).

FIGURA 5. Los habitantes de la colonia Viladomiu Nou, vistos desde la Torre del Amo, en 1905. Archivo Parque Fluvial del Llobregat. Reproducido en (Serra Rotés 2013).

En 1887 Tomàs Viladomiu muere y poco tiempo después sus hijos disuelven la sociedad Viladomiu e Hijos, para fundar Viladomiu Hijos, una sociedad conformada por Josep, Jacint y Marc Viladomiu que permanece activa 19 años. En 1896 muere Marc Viladomiu, y un año después se dividen las fábricas: Josep se queda con la Colonia Viladomiu Vell y Jacint con la Cau de Sant Marc, que a partir de ese momento evoluciona independientemente y pasa a conocerse como Viladomiu Nou. En su origen consta de una fábrica de planta baja y un piso, una cuadra anexa, un cobertizo para los batanes y otro para la turbina, además de dos bloques para trabajadores. En 1900 se construye la iglesia. En 1901 muere Jacint Viladomiu y su hijo Marc se hace cargo del negocio. En 1911, la obtención de un aprovechamiento hidráulico superior obliga a substituir la presa de madera de 1879 por una de hormigón más grande y progresivamente se va ampliando la fábrica y mejorando las instalaciones hidráulicas.

En 1933 Viladomiu Nou se amplía y alcanza el punto álgido de su desarrollo. Aunque las industrias se encuentran en pleno esplendor, a partir de la Segunda República, los amos pasan a un segundo plano y se distancian de las colonias, dejándolas en manos de sus hombres de confianza. Además, la inversión se reduce

\footnotetext{
${ }^{11}$ El Rerum Novarum es una carta encíclica promulgada por el Papa León XIII en 1891 en la que la iglesia se posiciona sobre las condiciones de las clases trabajadores y la justicia social. A pesar de que acepta el derecho laboral de formar uniones o sindicatos, también afirma su apoyo a la propiedad privada. Esta postura será desarrollada más tarde en el distribucionismo, una suerte de tercera vía entre el capitalismo y el socialismo que defiende que los bienes de producción deberían estar distribuidos lo más ampliamente posible entre la población.
} 
drásticamente. Esta actitud se mantiene durante el franquismo, cuando los amos recuperan sus vínculos con el poder, pero no reestablecen los sólidos lazos con las colonias. Debido a la mejora de los transportes y las comunicaciones sus estancias en la colonia se reducen drásticamente (Serra Rotés 2010). Quizás este momento marque el principio del declive del sistema, ya que el éxodo que comienzan los industriales, décadas después también afectará a las siguientes generaciones de trabajadores.

La Guerra Civil supone un paréntesis para las colonias. En 1936, la Generalitat colectiviza la colonia Viladomiu Nou y en la colonia Pons se derriban simbólicamente las murallas que nunca se vuelven a levantar (Serra Rotés y Viladés 2003). Esta época se cierra drásticamente con el final de la guerra. La autarquía del franquismo favorece los negocios de las colonias, posponiendo su declive hasta las últimas décadas del siglo XX. Sin embargo, este período se caracteriza por el endurecimiento del sistema paternalista. Serán los tiempos del silencio, el autoritarismo y la represión (Serra Rotés 2010, p. 246).

Es habitual explicar la decadencia de las colonias como consecuencia de la crisis del sector textil que sufre Catalunya en el último tercio del siglo XX. Sin embargo, se plantea aquí una hipótesis complementaria: la crisis de las colonias es la de su modelo de cooperación. El aislamiento y jerarquía que caracterizan su génesis, devienen obsoletos en la era de la producción biopolítica ${ }^{12}$, donde las plusvalías de la producción inmaterial emergen en los encuentros cotidianos casuales, vinculando trabajo, ocio y cultura (Hardt y Negri 2009). El modelo de gobernanza paternalista, exitoso durante la era de la producción industrial, ya no es un modelo de cooperación efectivo para la era postindustrial; más bien se manifiesta como un lastre para la producción, contra el que la sociedad civil reacciona reivindicando las colonias textiles, de nuevo de forma horizontal.

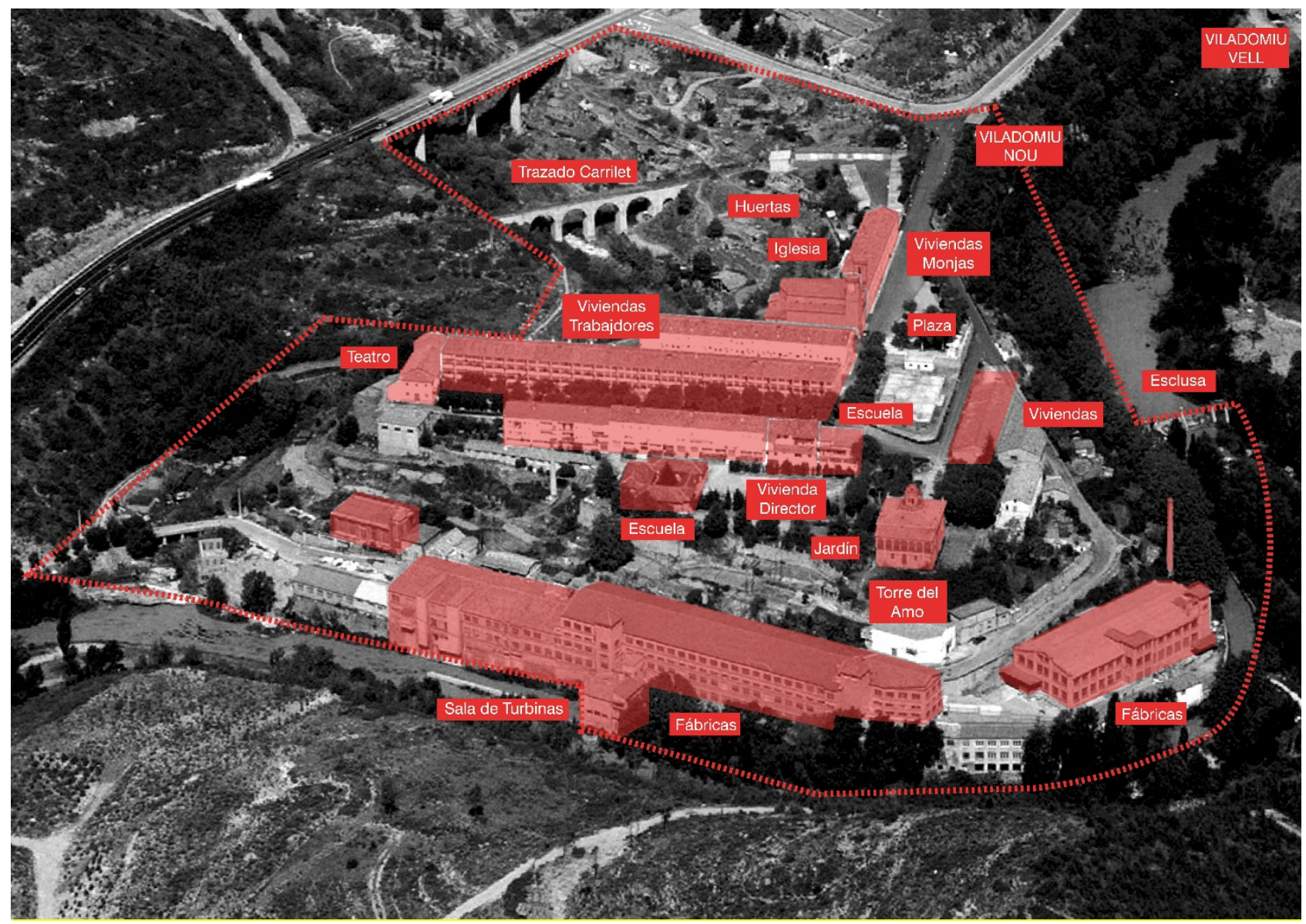

FIGURA 5. Viladomiu Nou. Anotaciones sobre imagen aérea del PDU de las Colonias del Llobregat (Vall, Sabate et al. 2007)

12 Hardt y Negri (2009, p. 73) definen la producción biopolítica basándose en la reinterpretación de la idea de biopolítica de Michel Foucault : "Nuestra lectura no sólo identifica la biopolítica con las potencias productivas localizadas de la vida - es decir, la producción de afectos y lenguajes a través de la cooperación social y de la interacción de cuerpos y deseos, la invención de nuevas formas de relación con uno mismo y con los demás, etc.-, sino que afirma también la biopolítica como la creación de nuevas subjetividades que se presentan a vez como resistencia y como desubjetivación." 


\section{LA COOPERACIÓN HORIZONTAL EN LA ERA DE LA PRODUCCIÓN BIOPOLÍTICA}

El sistema de colonias textiles del Baix Berguedà cierra el siglo XX sumido en una profunda crisis. Las condiciones que habían dado lugar a esta singular secuencia de recintos industriales cambian y su modelo de gestión no es capaz de adaptarse a la nueva realidad. Sin embargo, muchas de las colonias continúan siendo núcleos de población vivos y con una comunidad local dispuesta a reivindicarlas.

Tras el declive de los años 80 la propiedad de la colonia se diversifica. Algunos municipios se hacen con el espacio público, en otros casos las viviendas se venden a los trabajadores y algunas naves se alquilan o son adquiridas por la administración pública. Como afirman Vall y Sabaté: "Las inversiones efectuadas en las colonias durante esta fase son de estricta supervivencia. Los vecinos asumen de forma individual o colectiva, a través de las asociaciones, la rehabilitación del parque residencial. El antiguo fabricante dedica parte de las rentas generadas por el alquiler del parque industrial a su mantenimiento mínimo. Los ayuntamientos emprenden con dificultades la adecuación básica de los espacios públicos y de algunos edificios deteriorados" (Sabaté Bel y Vall Casas 2014, p. 36).

Con el cierre de las fábricas la capacidad de cooperación se debilita de forma severa, ya que industriales, trabajadores y residentes pierden el objetivo que los unía para colaborar. En algunos casos surgen enfrentamientos entre trabajadores e industriales, al sentirse los primeros traicionados por unos "amos" que se habían autoproclamado sus patriarcas. Sin embargo, los lazos y la cohesión social surgida en algo más de un siglo de cooperación paternalista, suponen una herramienta capital para afrontar con más garantías la nueva situación.

En un artículo publicado en L'Erol, Carles Enrech (2005, p. 18) relaciona el nivel de consolidación del conjunto urbanístico de las colonias, con la rotación o movilidad de los obreros. Este hecho, refuerza la hipótesis de que aquellas colonias donde la inversión en servicios, espacio público y tejido residencial son superiores, configuran comunidades más estables. Lo mismo sucede con el tarannà del industrial. Como pone de manifiesto el testimonio de algunos agentes conocedores de las colonias ${ }^{13}$, aquellas en las que el amo tiene una relación más próxima con sus trabajadores, son las que mejor resisten el colapso del sistema. Al contrario, aquellas con mayor rotación de trabajadores (colonias de aluvión), que vienen y se van por temporadas o que ni siquiera residen en el recinto, son aquellas que sufren procesos de degradación y marginalización más severos. Históricamente los Vialadomiu fueron una de estas familias industriales próximas a la comunidad. Prueba de ello son los diversos testimonios que lo reiteran (Rabat Fàbregas 2005). En las reglas de juego que articulan la cooperación y garantizan la paz social se define el rescate social y la solidaridad como deberes morales del amo.

A finales de los años 90 del siglo pasado, con el objetivo de poner en valor el sistema de colonias, se impulsa el Parque Fluvial del Llobregat: "un nuevo operador supramunicipal de base local constituido inicialmente como patronato y posteriormente como consorcio, (que) asume el impulso y la coordinación de microproyectos públicos dirigidos esta vez a la materialización de un proyecto territorial propio. Se trata de actuaciones que presentan los siguientes rasgos comunes: son puntuales pero de amplio efecto difusor; se dirigen a la dotación de la estructura pública del parque (Oficina de turismo, Centro de interpretación y Ruta de las colonias); son selectivas y aprovechan las ventajas de la oportunidad; buscan la visibilidad de una disposición dispersa; y pretenden la máxima implicación ciudadana" (Vall Casas 2011, p. 133)

El año 2005 marca un punto de inflexión en la evolución de las colonias. Coincidiendo con el 150 aniversario de su origen (se toma como hito temporal la ley de colonias de 1855) un grupo diverso de agentes locales las reivindican como un patrimonio colectivo clave en el pasado, pero también para el futuro de Catalunya. Se celebran una serie de actos institucionales y lúdicos que persiguen dar a conocer este patrimonio, promover el reconocimiento de su papel capital en el proceso de industrialización, rendir homenaje a sus protagonistas, aglutinar a los interesados, sensibilizar a la sociedad de su valor,...(Miralda 2005). El monográfico que la revista cultural del Berguedà, L'Erol (VV.AA. 2005) dedica al 150 aniversario, ilustra el interés que suscitan y el capital simbólico que atesoran.

Quizás como consecuencia de este renovado interés por las colonias, durante la legislatura 2003-2007, la Generalitat encarga un Plan Director Urbanístico para las colonias del Llobregat (Vall Casas y Sabaté Bel et al. 2007) y posteriormente del Ter y Freser (Sabaté et al 2010). Se trata de planes supramunicipales, que

\footnotetext{
${ }^{13}$ Algunos datos utilizados en este apartado han sido obtenidos de la entrevista realizada el 25 de Abril de 2017 al arquitecto Pere Vall i Casas, estudioso y gran conocedor de las colonias; además de estar muy involucrado en su reivindicación.
} 
establecen el marco urbanístico de referencia general para la puesta en valor del sistema de colonias. El ente encargado de impulsar las directrices del primer PDU es el Consorcio del Parque Fluvial del Llobregat, del que forman parte "los Ayuntamientos implicados, la Generalitat de Catalunya, la Diputación de Barcelona, el Consejo Comarcal del Berguedà, y diversas entidades representativas de la sociedad civil local" (Sabaté Bel y Vall Casas 2014, p. 39).

La antigua Torre del Amo de Viladomiu Nou se rehabilita para acoger la sede del Consorcio del Parque Fluvial del Llobregat y un centro de interpretación, convirtiéndose en la cara y el cuerpo de las colonias textiles del Llobregat. (Rabat Fàbregas 2005). En lo que respecta a la antigua casa solariega Teixidor-Bassacs de Gironella, en la actualidad es una casa museo en la que se expone una colección de objetos que ilustra la historia de la industrialización del Berguedà durante los siglos XIX i XX, abarcando el mundo rural, la minería, el textil y el ferrocarril. Ambas arquitecturas tienen en común una actualización programática basada en los valores materiales e inmateriales del patrimonio cultural.

En el contexto de austeridad y recortes derivados de la reciente crisis económica, el consorcio del Parque Fluvial del Llobregat se desmantela y cede sus atribuciones a un Consorcio de Turismo. Esto supone un paso atrás en la construcción del proyecto territorial ${ }^{14}$. El desenlace de este relato está aún abierto y depende en gran medida de la capacidad de negociación de la comunidad local, que sin duda tiene un rol protagonista en la creación de un nuevo modelo de gobernanza que articule la cooperación de sociedad civil, sector público y sector privado. Es necesario encontrar nuevas formas de cooperar que respondan a las demandas del siglo XXI. Como afirman Hard y Negri "En la época de la producción biopolítica, las herramientas capitales ya no son el telar mecánico, la desmotadora de algodón o la prensadora de metales, sino herramientas lingüísticas, herramientas afectivas para construir relaciones, herramientas para pensar, etc" (Hardt y Negri 2009, p. 311)

En su origen, el sistema de colonias textiles representa la emergencia de una singular territorialidad, que extiende la urbanización a través del nervio de Catalunya, generando un "híbrido rural-urbano". Actualmente, la secuencia de colonias y pueblos estructurados por el río Llobregat en su paso por el Baix Berguedà, representa una "ciudad lineal" discontinua con una población de 17.000 habitantes (Vall i Casas, 2001, p. 112); una oportunidad, aún sin explotar, para re-articular territorialmente la Catalunya, ciudad de ciudades (Nel·lo 2002) desde los valores del patrimonio y el común.

\section{HACIA UNA TAXONOMÍA DE LAS FORMAS DE LA COOPERACIÓN}

\section{La vivienda-taller que lidera la cooperación dispersa de la producción preindustrial ${ }^{15}$}

La casa solariega Teixidor-Bassacs se encuentra en el número $1^{16}$ de la Plaça de la Vila de Gironella. Aunque se desconoce la fecha exacta de su construcción, se sabe que fue restaurada en 1800 y desde entonces mantiene la estructura general, aunque posteriormente ha sido objeto de al menos dos reformas importantes ${ }^{17}$. Por su ubicación en el núcleo histórico, se cree que es uno de los edificios más antiguos del mismo. La casa constaba de un bajo, dos plantas y un desván. En la planta baja estaba la cuadra de telares, un taller textil que en 1861 acogía diez telares manuales, un urdidor y una máquina para enrollar el hilo en los carretes $^{18}$. En la primera planta vivía el servicio y los hijos de la familia. En la planta segunda estaban los dormitorios separados de Raimunda Bassacs (1818-1883) y Joan Teixidor (1809 $\left.{ }^{19}-1891\right)$, además de un dormitorio que probablemente utilizase el mayor de los descendientes ${ }^{20}$.

La vivienda-taller ilustra con claridad algunas características de la sociedad de la época preindustrial. Como afirma Montaner (1985) cuando analiza la vivienda artesana del barrio gótico barcelonés, "el tipo de vivienda

\footnotetext{
${ }^{14}$ Durante los primeros años del Parque Fluvial del Llobregat, la Diputación de Barcelona lo reconoce como un "clúster turístico". El PDU tiene la vocación de superar esta fase inicial y "desarrollar un proyecto territorial propio" (Sabaté Bel y Vall Casas 2014, p. 40)

${ }^{15}$ Algunos datos utilizados en este apartado han sido proporcionados por Joan Ramón Ruiz, actual propietario de la casa-museo TeixidorBassacs, en las visitas realizadas los días 20 de enero y 14 de abril de 2018.

${ }^{16}$ Según consta en las escrituras, antes tuvo los números 4 y 9.

${ }^{17}$ Según se describe en una noticia publicada el 25 de octubre de 1926 en una publicación quincenal denominada "L’Eco de Gironella", en aquel entonces la casa estaba siendo objeto de una importante reforma en la que se le aplican los motivos decorativos rectangulares del acabado actual. Además, en el año 2004 (según fecha de proyecto), la casa fue sometida a otra importante reforma, en la que el desván se transforma en vivienda, abriendo un gran patio en la cubierta y ampliando las ventanas de la fachada lateral.

${ }^{18} \mathrm{En}$ aquel entonces el taller utilizaba $7500 \mathrm{Kg}$ de algodón anuales (Serra Rotés 2013).

${ }^{19}$ Dependiendo de la fuente consultada la fecha de nacimiento de Joan Teixidor es 1807 o 1809.

${ }^{20}$ Según el testimonio, recogido por Joan Ramón Ruíz, de una de las sirvientas de la casa, al menos Dolors Teixidor Bassacs salió de esta habitación cuando abandonó la casa familiar al casarse.
} 
va unido siempre estrechamente a la estructura familiar peculiar de cada período histórico". Antes del período industrial "la familia estaba entendida desde una concepción aún poco restrictiva y estaba constituida por los padres; los hijos; otros miembros consanguíneos como tíos, sobrinos, etc.; los oficiales y los aprendices; los criados y criadas; y a veces expósitos adoptados." Además, "la familia menestral o artesanal era al mismo tiempo unidad de producción, escuela de formación profesional, unidad tributaria y centro asistencial". Al igual que la tipología que analiza Montaner, la vivienda de Gironella es el reflejo de la familia menestral de la época e integra todas las actividades de su cotidianidad, agrupando residencia y trabajo. En ambas tipologías los usuarios se distribuyen espacialmente con una marcada jerarquía vertical. En el caso barcelonés la planta noble (en la que residen los cabeza de familia) ocupa la posición inmediatamente superior al taller (ubicado en planta baja) y en las plantas superiores disminuye progresivamente la importancia del miembro de la familia. La vivienda de Gironella materializa una jerarquía vertical ascendente más clara aún si cabe: en la primera planta (sobre el taller) se ubican los miembros menos importantes de la familia (descendientes y servicio), en la segunda planta están los progenitores, quedando por encima solo el desván (destinado a almacenaje y actividades complementarias de la fabricación textil o la vida rural). La planta segunda de la vivienda de Gironella también presenta una jerarquía horizontal en la que distribuye espacialmente a los miembros de la familia según su importancia. Llama la atención, en un período donde las figuras femeninas casi siempre permanecen supeditadas a las masculinas, que el dormitorio más importante de la casa (que da a la Plaça de la Vila y permite controlar visualmente el territorio hasta la colonia Bassacs) sea el de Raimunda. Esto se explica, al menos en parte, por el hecho de que ella fuese la Pubilla ${ }^{21}$ que hereda de los Bassacs la casa Pairal, a la que se muda Joan. Además, la fuerte personalidad que se le atribuye como mujer "emprendedora y trabajadora" 22 también justifica su rol de liderazgo en la familia. El salón comedor, que también se abre a la Plaça de la Vila, es el espacio social de la vivienda y la antesala del dormitorio de la matriarca. Las otras dependencias dan a calles secundarias y corresponden al dormitorio de Joan (conectado con el de Raimunda a través de un pasadizo semi-oculto), a otro dormitorio y a una cocina. Aunque la colonia Bassacs se inaugura en los años 60, la producción textil en el taller permanece hasta 1896.

En 1987 los padres de su actual dueño, Joan R. Ruiz, compran la casa a cuatro de los herederos de la familia Teixidor-Bassacs. Actualmente, es un museo donde Joan comparte su colección privada sobre la época preindustrial en el Berguedà. En la antigua cuadra de telares, entre otros utensilios, se expone un antiguo telar, aún en funcionamiento. La primera planta acoge una exposición permanente de utensilios y documentos que ilustran la vida rural del Berguedà antes de la industrialización, la minería y la llegada del ferrocarril. En la segunda planta, que aún conserva algunas de las pinturas de los paramentos originales, Joan proyecta una reforma con la intención de alquilar a huéspedes las habitaciones donde dormía el matrimonio (Canturri 2016). La planta bajo-cubierta, tras una importante reforma realizada en el año 2004, acoge la vivienda de Joan.

\section{La torre que vigila la cooperación jerárquica de la producción industrial paternalista}

Aunque no fue concebida como vivienda permanente, la torre de Viladomiu Nou constituía la residencia de sus propietarios cuando estaban en la colonia (generalmente en verano y una vez a la semana). Aunque en 1899 ya se estaba trabajando en su construcción, la torre se estrenó en 1902 (Generalitat de Catalunya 2018) y además de vivienda, su función principal fue la de representar el poder de los industriales y controlar todos los movimientos en la colonia. El edificio, construido con piedra calcárea extraída de los márgenes del Llobregat y ladrillo, consta de una planta de acceso -con usos secundarios y las habitaciones del servicio y los descendientes menores-; una planta noble -con un cuarto para el servicio, un dormitorio para los hijos mayores, otro para invitados, el dormitorio de los Viladomiu y un despacho-; un desván y un mirador de planta cuadrada con las esquinas achaflanadas que sobresale en la cubierta de teja árabe a cuatro aguas- desde donde se divisa toda la colonia-. La fachada principal se orienta al noroeste y está precedida por un jardín. En la fachada posterior, orientada al sureste, se adosó a la planta cuadrada un volumen rectangular de dos niveles. Se desconoce la fecha exacta de este añadido, pero en el año 1905 aún no existía ${ }^{23}$. La planta se articula en torno a un núcleo central que distribuye las circulaciones y genera un gran vestíbulo que organiza los accesos.

Cabe destacar que en paralelo a las circulaciones principales a través del espacio central, existe un recorrido secundario concéntrico que atraviesa las dependencias a través de puertas semi-ocultas. Era utilizado por un servicio que debía pasar casi desapercibido para los amos y sus visitas. También llama la atención que la escalinata señorial de la casa, en los últimos tramos que acceden al mirador, se transforma en dos sobrias

\footnotetext{
${ }^{21}$ Tradicionalmente en Catalunya, cuando la familia no tenía un primogénito varón o Hereu (heredero), era la hija mayor o Pubilla, la que heredaba la casa y la fortuna familiar.

${ }^{22}$ En el artículo Les colònies industrials a Catalunya (Serra Rotés 2010), se define con estos dos atributos. Además, durante una reciente visita a la Casa Museo, su propietario destacó el rol de Raimunda como matriarca de la familia.

23 Según la fotografía de 1905 del Archivo del Parque Fluvial del Llobregat, reproducida en (Serra Rotés 2013).
} 
escaleras de dimensiones mínimas. Este matiz permite intuir que más allá de la vigilancia real que pudiese ejercer el amo -que probablemente casi nunca subiese esos discetos tramos de escalera-, el mirador es principalmente un dispositivo de control que actúa a modo de panóptico. Sin importar si realmente existe un vigilante o no, lo relevante es que los trabajadores se sientan observados. Al igual que la casa solariega Teixidor-Bassacs, la Torre del Amo es la sede desde la que, al menos de forma simbólica, se lidera el modelo de producción de la época. Sin embargo, en este caso ya no se trata de una vivienda productiva y la fabricación no ocupa el mismo edificio que la gestión y la residencia.

En los años ochenta, tras el abandono de la Torre durante la crisis de las colonias, se venden los muebles y el edificio entra en un período de deterioro. Más tarde es adquirida por el Ayuntamiento de Gironella y se le otorga la protección de Bien Cultural de Interés Local. Tras la aprobación del PDU y la creación del consorcio del parque fluvial de las colonias del Llobregat, la Torre del Amo se restaura ${ }^{24}$ y acoge la sede de la institución y un centro de interpretación. En las antiguas carboneras en el sótano de la torre se instala una exposición permanente que describe la vida en las colonias. El recorrido por las plantas superiores permite imaginar cómo era la vida en las colonias cuando estas estaban en funcionamiento. A pesar de que en 2013 desaparece el consorcio ${ }^{25}$, el centro de interpretación de las colonias del Llobregat todavía se puede visitar.

\section{La ida y vuelta del común a través de los hábitats del textil.}

Las dos tipologías relatan un proceso evolutivo que parte de la vivienda-taller preindustrial, pasa por la torre del período industrial y evoluciona hasta los museos y centros de interpretación del patrimonio cultural en la actualidad. En el primer estadio, destaca la mixtura de usos y flexibilidad funcional de la tipología que asume el liderazgo de un modelo productivo disperso en el territorio. Esto se pierde en la segunda fase, con la concentración de la producción textil en las colonias y la tecnificación de los procesos de fabricación, que requiere la especialización espacial y el surgimiento de nuevas tipologías (fábricas, casas de obreros en función del rango, iglesias, cafés...). Además, la deriva jerárquica del modelo de cooperación que caracteriza este período hace que la tipología de la Torre del Amo concentre un gran valor simbólico. Prueba de la importancia que cobran las relaciones públicas y el carácter representativo de la nueva tipología, es la existencia de un dormitorio para visitas en la planta noble, conocido como habitación del obispo (en honor al huésped que la utilizó tras la consagración de la iglesia de la colonia). Al igual que sucede con el proletariado en la cadena de montaje, la racionalización de la industria también especializa la casa, convirtiéndola en una tipología con la función principal de representar el poder (económico y político) del amo, para asegurar la fidelidad de los trabajadores y la admiración de posibles compradores. Aunque la arquitectura reduce drásticamente el número de funciones que alberga, aumenta su superficie (la ocupación en planta de la Torre del Amo es casi tres veces la vivienda-taller de Gironella) y presenta un mayor esfuerzo compositivo. Al igual que observa Montaner en Barcelona en la casa de vecinos entre medianeras del siglo XIX, la Torre del Amo introduce recursos neoclásicos como la simetría (en fachada y en planta ${ }^{26}$ ).

Tras el derrumbe del modelo de producción industrial y la emergencia de la cooperación horizontal del siglo XXI, surgen de nuevo las tipologías mixtas y no jerarquizadas (Montaner y Muxí 2014). La reforma de la Torre de Viladomiu Nou la transforma en un equipamiento comunitario al servicio de la colonia y el paisaje cultural al que pertenece, que puede abarcar usos tan diversos como una oficina de información turística, un espacio donde impartir cursos o seminarios, un museo con una exposición permanente, o un espacio para la celebración de eventos. La vivienda de Gironella es un museo, la residencia de su dueño y es probable que pronto complemente estas funciones con el hospedaje temporal de visitantes.

También se observa una evolución en la relación de las tipologías con el territorio. En el período preindustrial, la vivienda-taller era el nodo en el que confluían los flujos productivos provenientes de las masías dispersas en el territorio. Tras la industrialización, la red de masías se fragmenta ${ }^{27}$ y la producción se concentra en el eje lineal marcado por el cauce del río, y aunque la comercialización y el acopio de materias primas extienden sus tentáculos por el territorio, las colonias buscan aislarse del exterior y tienden a producir de forma autónoma. En el período postindustrial, los nuevos proyectos para las dos tipologías buscan conectarlas de nuevo con el territorio.

\footnotetext{
24 "La restauració de l'edifici va ser finançada pel programa FEDER de la Unió Europea, la XBMQ de la Diputació de Barcelona i la Generalitat de Catalunya a través del programa PLADETUR" (Soler, Santamaria y Canal 2009).

${ }^{25}$ «Torre de l'Amo de Viladomiu Nou». Consorci del Parc Fluvial del Llobregat. [http://www.parcfluvial.cat/ Consulta: 21 octubre 2014 . En la actualidad este enlace no está disponible].

${ }^{26}$ La doble simetría de la planta cuadrada se rompe con el añadido rectangular en la fachada sureste.

${ }^{27}$ A pesar de que los trabajadores de las colonias mantienen sus vínculos con sus masías de procedencia (Vall i Casas 1999).
} 
Estas dos tipologías son la manifestación espacial de los cambios en las dinámicas productivas y los modelos de cooperación de su época. En los tiempos de la cooperación rural dispersa, la vivienda concentra residencia, liderazgo, producción e intercambio, acogiendo bajo un mismo techo a trabajadores y menestrales que comparten experiencias en el devenir cotidiano. Cuando, con la industria, emerge la cooperación jerárquica paternalista, los trabajadores son expulsados de la sede del textil, siendo para ellos toda una incógnita lo que sucede dentro de las paredes de una torre a la que solo puede acceder los amos, sus visitas y el servicio ${ }^{28}$. La nueva arquitectura concentra todos los esfuerzos en ejercer el liderazgo del sistema. En paralelo se crean otros espacios para que los miembros expulsados del hogar del patriarca puedan producir, vivir y convivir. Cabe finalizar esta reflexión preguntándose acerca de estos otros espacios del textil: las viviendas de los trabajadores, las fábricas y los lugares de la convivencia (los parques, huertos, cafés, lavaderos,...) ya que probablemente en ellos se encuentren algunas claves que expliquen el regreso actual, en la era postindustrial, de las arquitecturas multifunción que ponen de nuevo el espacio al servicio del común. Sin embargo, esto ya será objeto de otro artículo.

\footnotetext{
${ }^{28}$ Según el testimonio de Juan García, uno de los antiguos trabajadores de la colonia, al menos durante el período posterior a la Guerra Civil y hasta el cierre de la fábrica, los trabajadores de la colonia no podían acceder al edificio.
} 

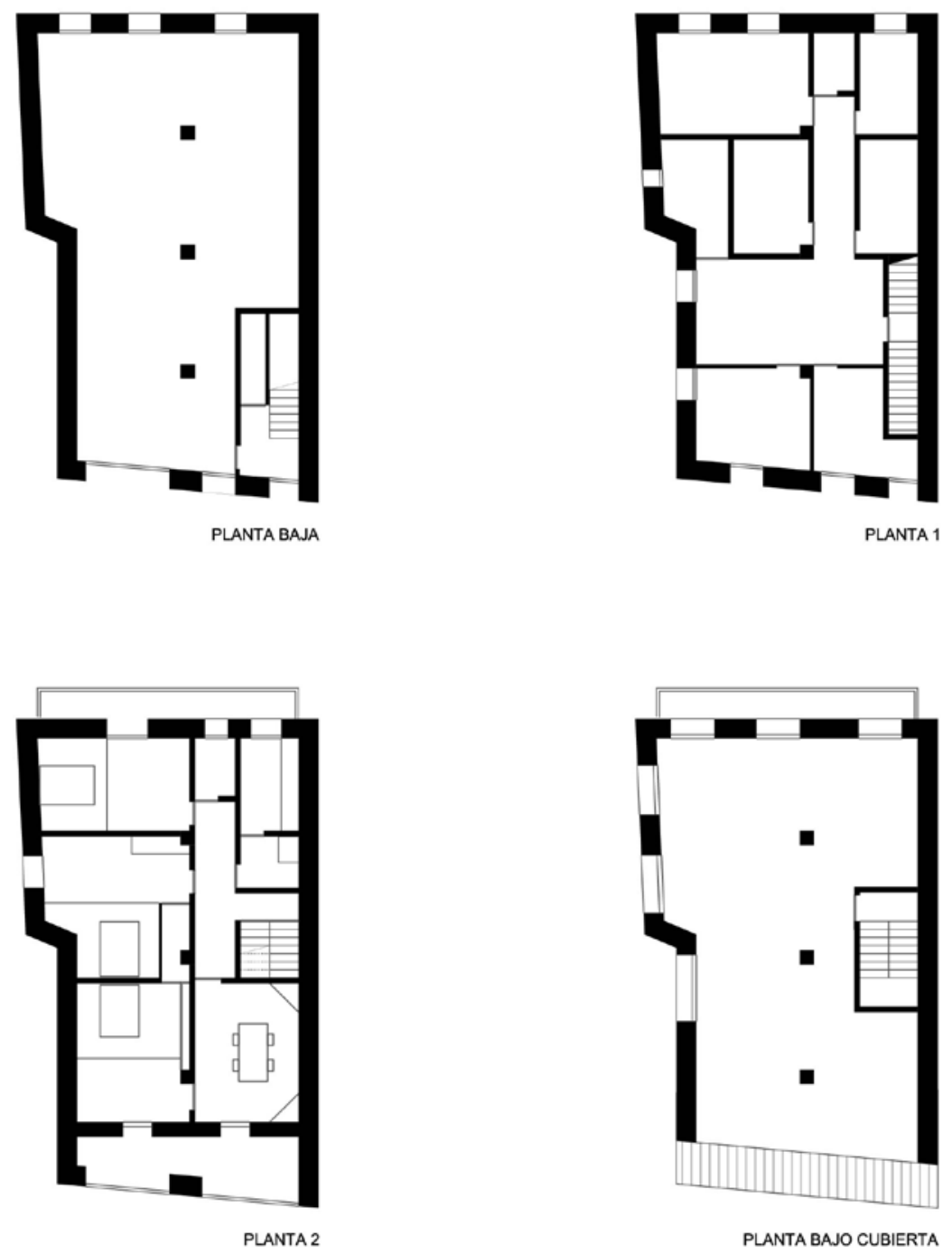

CASA PAIRAL SXIX 

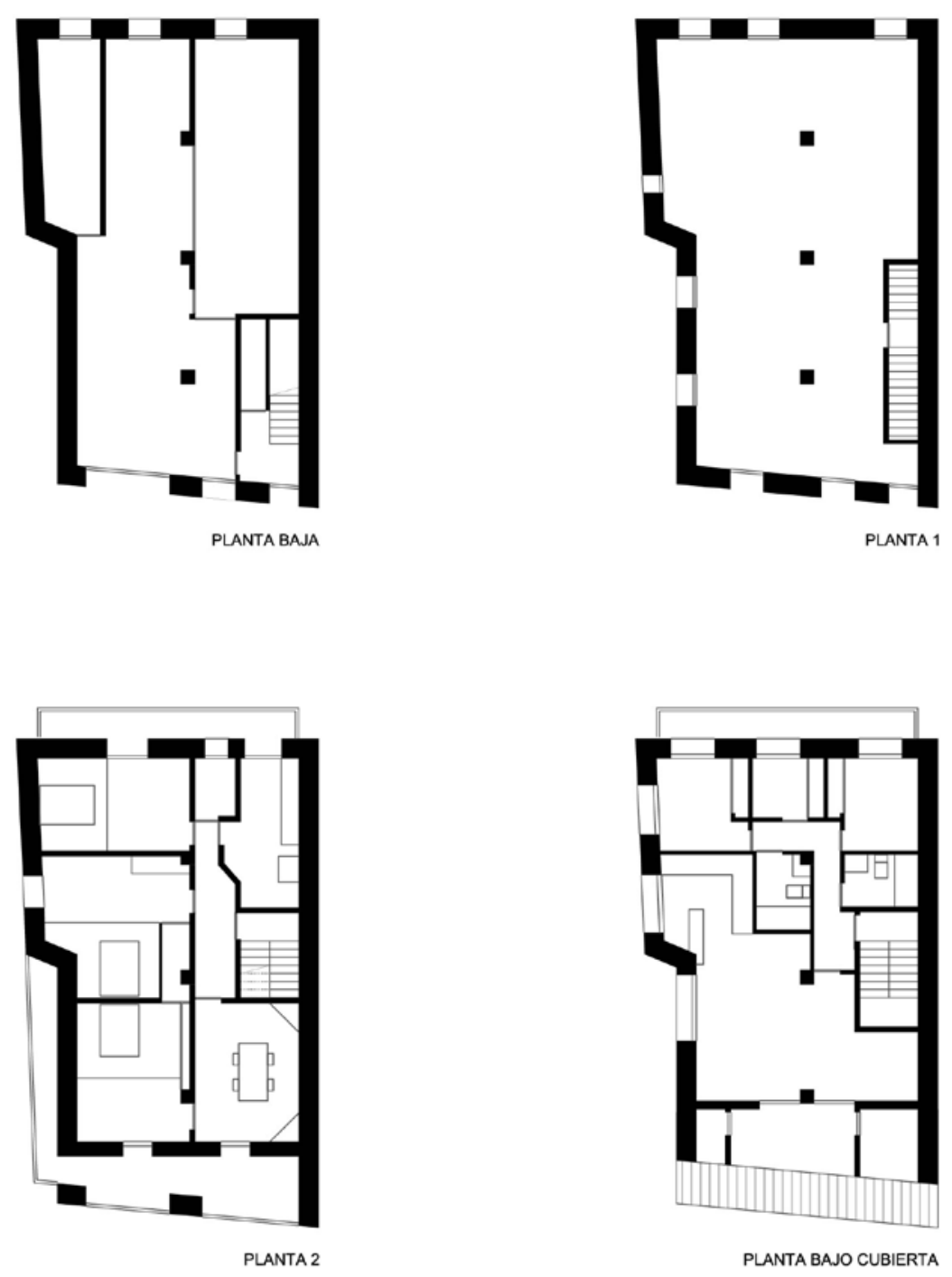

CASA PAIRAL SXXI 

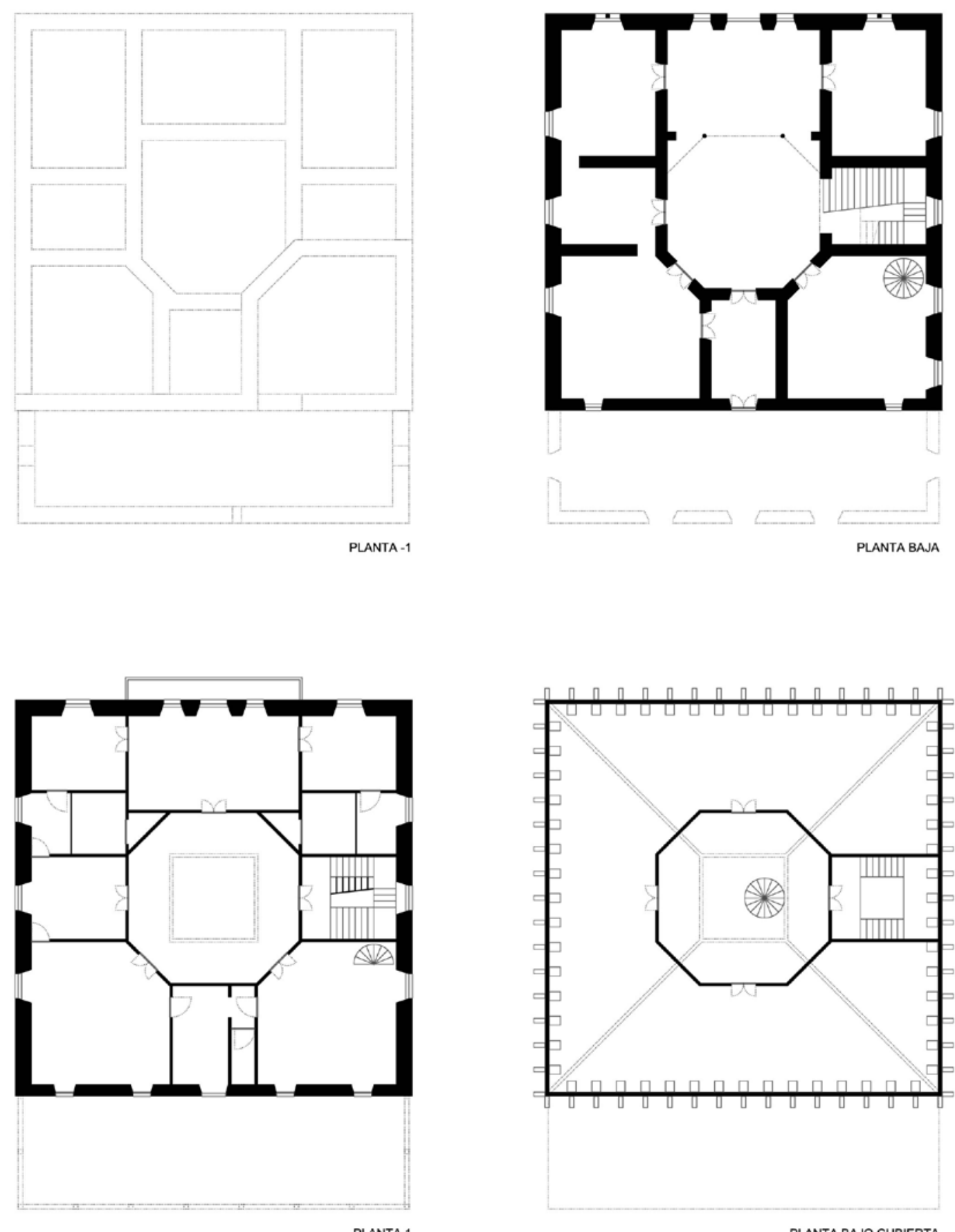

$\begin{array}{llllll}1 & 1 & 1 & 1 & 1 & 1\end{array}$

TORRE AMO PRINCIPIOS SXX 

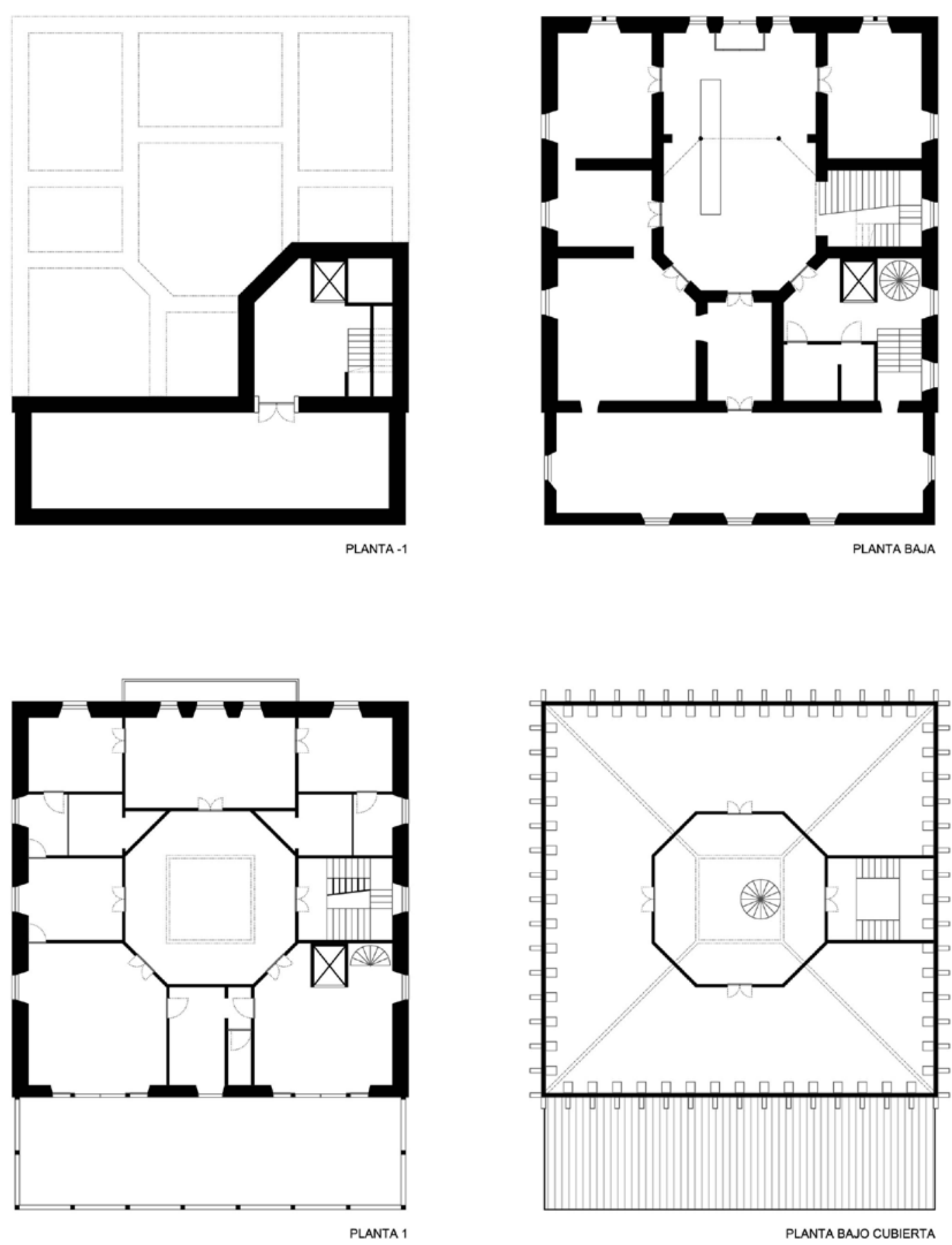

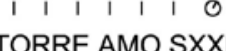




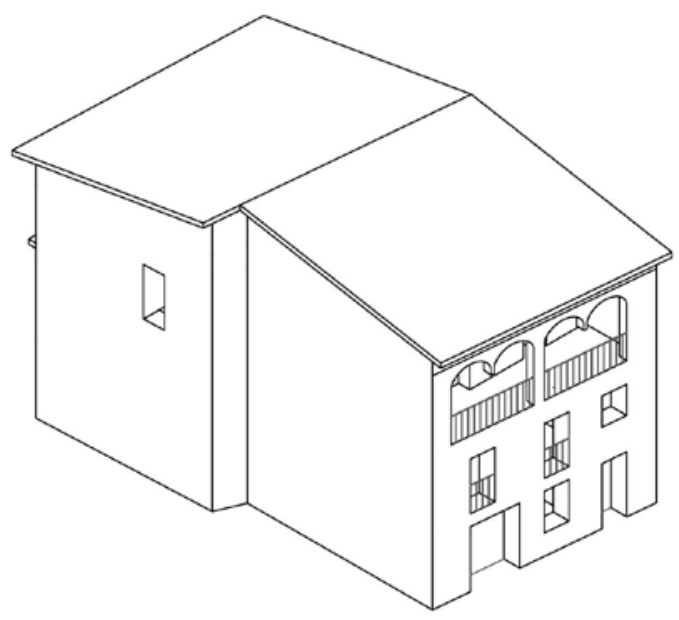

TEIXIDOR BASSACS SXIX

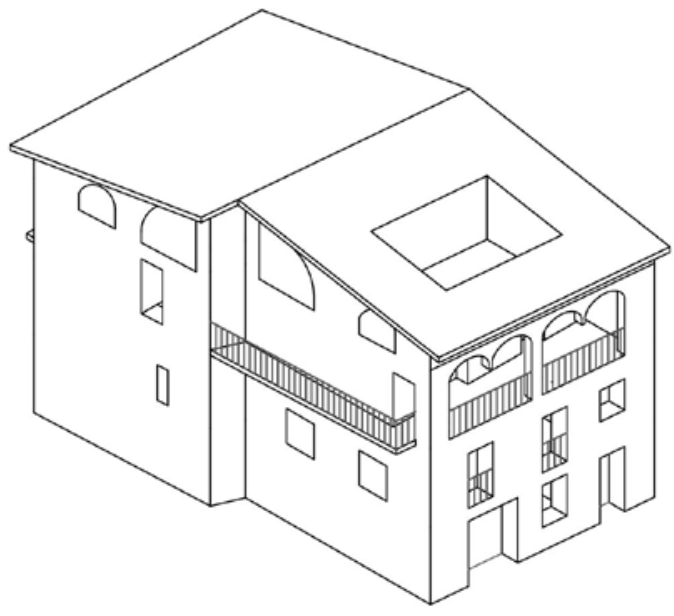

TEIXIDOR BASSACS SXXI 


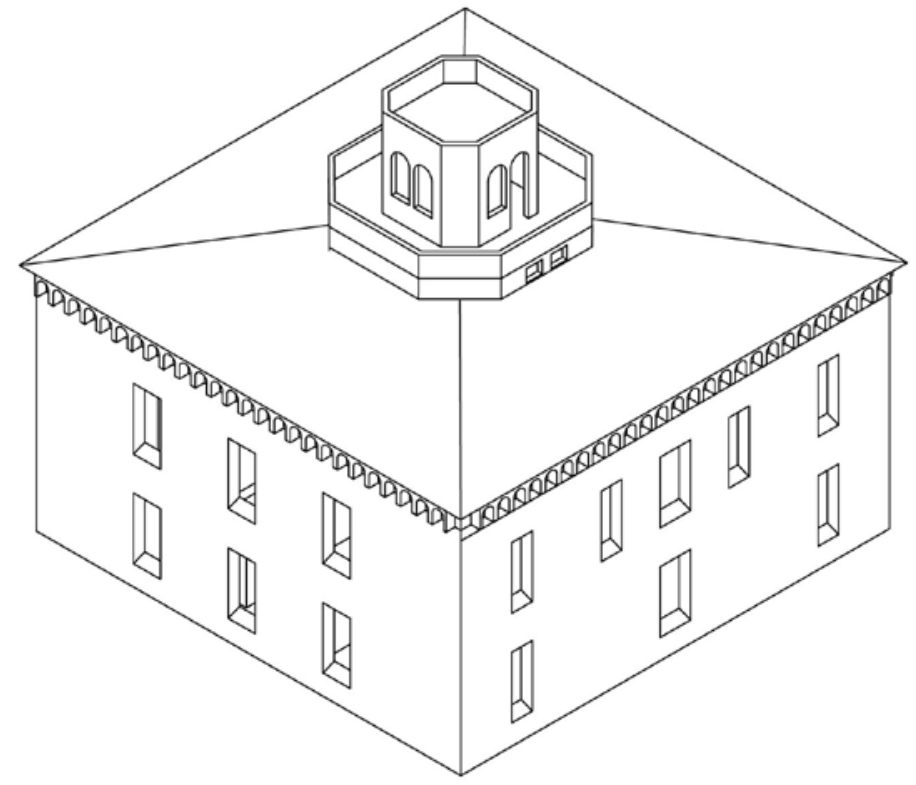

TORRE AMO PRINCIPIOS SXX

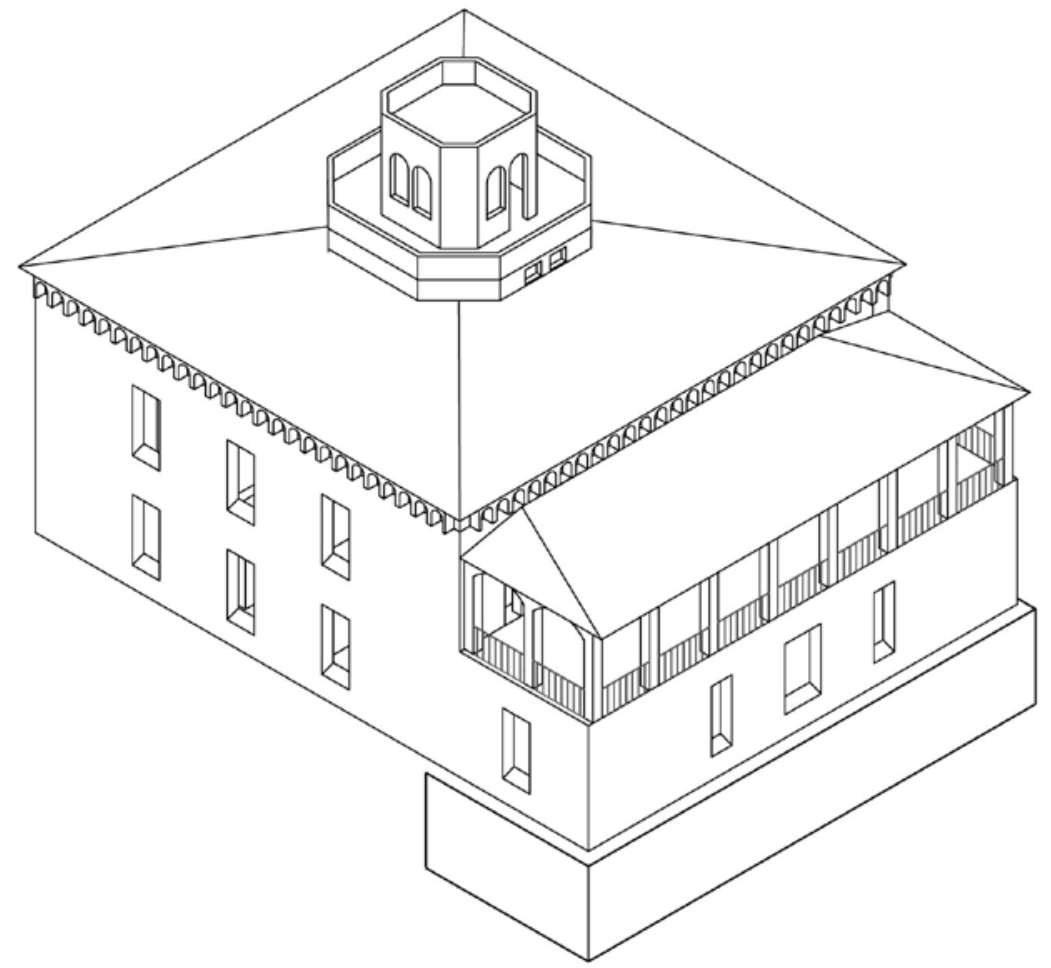

l 1 I 1 I ।

TORRE AMO SXX 


\section{BIBLIOGRAFÍA}

BEVIR, M., 2012. Governance: A Very Short Introduction. S.I.: OUP Oxford. Very Short Introductions. ISBN 9780191646294.

BRUGUÉ, Q., GOMÀ, R. y SUBIRATS, J., 2005. Gobernar ciudades y territorios en la sociedad de las redes. Revista del CLAD Reforma y Democracia, no. 32.

CANTURRI, M., 2016. El taller dels records. El punt avui [en línea], Disponible en: http://www.elpuntavui.cat/territori/article/-/957243-eltaller-dels-records.html?tmpl=print

CASTRO-COMA, M. y MARTí-COSTA, M., 2016. Comunes urbanos: de la gestión colectiva al derecho a la ciudad/Urban common: the collective management of the right to the city. EURE, Revista Latinoamericana de Estudios Urbano Regionales [en línea], vol. 42, no. 125, pp. 131-153. ISSN 02507161. DOI 10.4067/S0250-71612016000100006. Disponible en:

http://search.proquest.com/docview/1753972899?accountid=14598.

CLUA I MERCADAL, J., 1992. Les colonies industrials al Berguedà: estudi d'una transformació econòmica i urbana. Treballs de la Societat Catalana de Geografia, vol. VII, no. 33-34, pp. 145-170. ISSN 2014-0037.

COMAS, F., 2005. Les colonies industrials, nuclis d ' atracció de població. L’ÉEol, vol. 86-87.

CORREA LLOREDA, L., 2003. Las Colonias Industriales del Llobregat: de la fábrica textil al parque fluvial. Cimbra, vol. 350, pp. 24-29.

DEMATTEIS, G., 2006. En la encrucijada de la territorialidad urbana. Bitácora Urbano Territorial [en línea], vol. 10, no. 1, pp. 53-63.

Disponible en: http://www.redalyc.org/articulo.oa?id=74831071005\%0ACómo.

ENRECH, C., 2005. les colònies industrials i el projecte social paternalista. L’Erol, vol. 86-87.

FERRER, L., 2005. Acumulació de capital i construcció de les colonies textils. L’Erol, vol. 86-87.

FOUCAULT, M., 1979. Vigilar y castigar. Nacimiento de la prisión. París: s.n. ISBN 978-84-323-0332-6.

GENERALITAT DE CATALUNYA, 2018. Cercador Inventari del Patrimoni Arquitectónic. Fitxa Torre de l’Amo Viladomiu Nou. [en línea]. [Consulta: 1 mayo 2018]. Disponible en:

http://invarquit.cultura.gencat.cat/Cerca/FitxaGeneral?index=5\&consulta=MSUxK3ZpbGFkb21pdSUyKy0xJQ\%3D\%3D\&codi=3328.

HARDT, M. y NEGRI, A., 2009. Commonwealth. El proyecto de una revolución del común. Akal. Madrid: Akal. ISBN 978-84-460-3230-4.

HESS, C., 2008. "Mapping New Commons." Presented at The Twelfth Biennial Conference of the International Association for the Study of the Commons, Cheltenham, UK. Syracuse University: SURFACE, pp. 14-18. ISSN 1556-5068. DOI 10.2139/ssrn.1356835.

KOOIMAN, J., 2005. Gobernar en gobernanza [en línea]. 2005. Madrid: Estudios Goberna. ISBN 84-7351-239-1. Disponible en:

http://www.redalyc.org/articulo.oa?id=74831071005\%0ACómo.

MIRALDA, Á., 2005. 150 anys de Colonies Industrials a Catalunya. L’Erol, vol. 86-87.

MONTANER, J.M., 1985. Escaleras, patios, despensas y Alcobas. Un análisis de la evolución de la casa artesana a la casa de vecinos den Barcelona. Arquitecturas Bis,

MONTANER, J.M. y MUXÍ, Z., 2014. Arquitectura y Política. Barcelona: s.n. ISBN 978-84-252-2437-9.

NEL.LO, O., 2002. Cataluña, ciudad de ciudades [en línea]. Lleida: Milenio. [Consulta: 9 abril 2018]. ISBN 8497430255. Disponible en: http://cataleg.upc.edu/record=b1209232 S1*spi.

OSTROM, E., 1990. El gobierno de los bienes comunes. La evolucion de las instituciones de accion colectiva. México D.F.: FCE. ISBN 978607-16-0617-4.

RABAT FÀBREGAS, J., 2005. Nous usos per a la torre de Viladomiu Nou. L’Erol, vol. 86-87.

ROCAMONDE, J., SABATÉ, J. y ORDUÑA, P., 2017. La Khôra de los comunes. Un análisis de los procesos cooperativos en la construcción y reivindicación de tres paisajes productivos vinculados al Llobregat (TFM, MBarch) [en línea]. Barcelona: ETSAB-UPC. Disponible en: https://upcommons.upc.edu/handle/2117/112871.

SABATÉ BEL, J., 2005. De la preservación del patrimonio a la ordenación del paisaje. Revista Identidades. Territorio, Cultura, Patrimonio., vol. 1, pp. 15-33.

SABATÉ BEL, J., 2007. Paisajes culturales y desarrollo local: ¿Alta costura o prêt a porter? Revista Labor \& Engenho, no. v.1, n.1, pp. 5176.

SABATÉ BEL, J. y VALL CASAS, P., 2014. Colonias postindustriales: crisis y revalorización. Labor \& Engenho, pp. 35-48.

SABATÉ, J., CCRS ARQUITECTES y SERVEIS TĖCNICS DE LA DIRECCIÓ GENERAL D'URBANISME, 2010. Pla Director Urbanístic de les Colònies del Ter idel Freser [en línea]. 2010. S.I.: s.n. Disponible en:

http://ptop.gencat.cat/rpucportal/AppJava/cercaExpedient.do?reqCode=veureDocument\&codintExp=228941\&fromPage=load

SAUER, C.O., 1925. The morphology of landscape. University of California Publications in Geography [en línea], vol. 2 (2), pp. 19-54. ISSN 0717-6554. Disponible en: http://polis.revues.org/5015.

SENNETT, R., 2012. Juntos. Rituales, placeres y política de cooperación. Anagrama. Barcelona: Anagrama. ISBN 978-84-339-6348-2.

SERRA ROTÉS, R., 2010. Les colònies industrials a Catalunya. Catalan Historical Review, vol. 4, no. 2011, pp. 241-255. ISSN 2013407X. DOI 10.2436/20.1000.01.53

SERRA ROTÉS, R., 2013. Els orígens de la industrialització tèxtil de Gironella : Cal Metre , Cal Bassacs ,Viladomiu Vell i Viladomiu Nou.

L'Erol, vol. 118, no. Revista Cultural del Berguedà, pp. 20-30.

SERRA ROTÉS, R. y VILADÉS, R., 2003. La colònia Pons (Puig-Reig). L’Erol, vol. 86-87, pp. 56-60.

SOLER, E., SANTAMARIA, N. y CANAL, M., 2009. La Torre de I' Amo de Viladomiu Nou . Una proposta d'interpretació històrica sobre el moviment obrer a les colònies. L’Erol [en línea], vol. 102, no. 1909 La Setmana Tràgica, pp. 30-31. Disponible en: http://www.raco.cat/index.php/Erol/issue/view/15103/showToc.

SUBIRATS, J. y RENDUELES, C., 2016. Los bienes comunes ¿Oportunidad o espejismo? Icaria Edi. Barcelona: s.n. ISBN 978-84-9888736-5.

TARRAGÓ, S., PALLÉS, C., DEL CALLEJO, J.C., PRIETO, L. y BASCONES, A., 1987. Les colonies industrials catalanes. Espais: revista del Departament de Política Territorial i Obres Públiques [en línea], vol. 5. Disponible en: http://www.raco.cat/index.php/Espais/article/viewArticle/91048/0.

UNESCO, 2006. Textos básicos de la Convención Del Patrimonio Mundial de 1972. PArís: Ministerio de Cultura.

VALL CASAS, P., 2011. Revisión metodológica sobre el planeamiento de un paisaje cultural. El Plan Director Urbanístico de las colonias del Llobregat. Urban [en línea], no. 13, pp. 122-136. ISSN 2174-3657. Disponible en: http://polired.upm.es/index.php/urban/article/view/881.

VALL CASAS, P. y SABATÉ BEL, J., 1997. El sistema de colònies tèxtils del Baix Berguedà. Gènesi i revalorizació. [en línea]. S.I.: ETSAB UPC. [Consulta: 25 marzo 2017]. Disponible en: http://oden.cbuc.cat/mendeley/enviaamendeley.php?bibid=.b1133096\&inst=UPC\&llen=eng.

VALL CASAS, P., SABATÉ BEL, J., VECSLIR PERI, L., BENAGES, M., LLOP, A. y TORT, E., 2007. Pla Director Urbanístic de les Colònies del Llobregat. 2007. S.I.: s.n.

VALL I CASAS, P., 1999. De colònies tèxtils a Parc Fluvial. El sistema de Colònies Tèxtils del Baix Berguedà. Gènesi i revaloracio. Barcelona: Associació d’Enginyers Industrials de Catalunya. ISBN 84-267-1209-6.

VV.AA., 2005. L’Erol 86-87.150 anys de colònies industrials. 2005. S.I.: s.n. 